\title{
Expeditious damage index for arched structrures based on dynamic identification testing
}

\author{
E. Giordano ${ }^{1}$, N. Mendes ${ }^{2}$, M. G. Masciotta ${ }^{3}$, F. Clementi ${ }^{1}$, N. H. Sadeghi ${ }^{4}$, R.A. Silva ${ }^{2}$, D. V. \\ Oliveira $^{2}$ \\ ${ }^{1}$ Dept. of Civil and Building Engineering, and Architecture, Polytechnic University of Marche, \\ Ancona, Italy. \\ e-mails: e.giordano@pm.univpm.it; francesco.clementi@univpm.it \\ ${ }^{2}$ ISISE, Department of Civil Engineering, University of Minho, Guimarães, Portugal. \\ e-mails: nunomendes@civil.uminho.pt, neda.hsadeghi@gmail.com, ruisilva@civil.uminho.pt, \\ danvco@civil.uminho.pt \\ ${ }^{3}$ Dept. of Engineering and Geology, University "G. d'Annunzio" of Chieti-Pescara, Italy. \\ e-mail: g.masciotta@unich.it \\ ${ }^{4}$ Dept. of Art and Architecture, Yazd University, Yazd, Iran. \\ e-mail: neda.sadeghi@yazd.ac.ir
}

\begin{abstract}
This paper presents a new damage detection index for arched structures, which can easily and quickly provide an estimate of their integrity. The results from eight laboratory tests performed on both reinforced and unreinforced adobe arches are used to define the index. The arches are damaged up to collapse using pseudo-static test cycles carried out by applying progressive controlled displacements at third span. The test records allow to follow the stiffness degradation of each arch by plotting the relative force-displacement curves, as well as to track their frequencies variation during the damage evolution by means of dynamic identification tests performed at the end of each cycle. The new index considers the bending moment as the main cause of damage for the analysed arches; therefore, starting from the bending stiffness, a damage indicator was developed and experimentally validated, as function of the frequency reduction, respect to the undamaged scenario. Finally, the index is also validated for different types of arch collapse mechanisms through Finite Element Modeling.
\end{abstract}

Keyword: Adobe arches; Dynamic identification; Operational Modal Analysis; Damage detection; Stiffness-frequency correlation; Pseudo-static tests; Finite Element Method 


\section{Introduction}

Observing the damage suffered by numerous historical and monumental structures after the last seismic events, it is evident how the preservation of built heritage has become a fundamental issue $[1,2]$. Earthquakes turn out to be the main cause of serious damage, but not the only one, indeed even the exposition to environmental factors or new loading conditions can originate small cracks (at different levels) than can worsen into significant and irreversible damages. Thus, it is essential to elaborate easy and fast methods able to analyse in real or nearly-real time the structural capacity, in order to intervene promptly in case of damage onset, thereby avoiding expensive belated restoration works. Resorting to a simple yet efficient modal-based parameter for the timely identification of the global strength loss of the monitored structures can be of great help to achieve this purpose.

When the objects of study are heritage structures, the experimental data for the system's characterization must be acquired via non-invasive techniques to follow the conservation principles and respect the historical value of the construction. The data that follow these requirements can be obtained from dynamic field testing procedures, which aim at estimating the dynamic parameters of the structure (i.e. natural frequencies, mode shapes and damping ratios), and are extremely sensitive to any mass or stiffness change induced by damage [3]. Dynamic testing is a global technique that allows to extract these parameters from the analysis of the vibration signals recorded by accelerometric sensors deployed at strategic locations across the structure. Such sensors, which can be wired back to a single centralised data acquisition system or not, record the vibration response of the building to freely available ambient excitations (e.g. road traffic, wind, micro-tremors, etc.). The synchronized response processes are subsequently processed in time and/or frequency domain via output-only identification techniques for the estimation of the most meaningful modal features of the system. The continuous repetition of dynamic measurements over time is commonly referred to as structural health monitoring. In this regard, there are two types of monitoring strategies that can be adopted: long-term and short-term. The latter is the most used in the engineering practice, since it can be carried out in one or a few days even using a limited number of sensors, that can be moved across the structure to reach a high spatial density and obtain sufficient information for the system's characterization [4-8]. The former consists in a continuous data acquisition process for a period normally greater than one year, allowing to observe not only the variation of dynamic proprieties over time, but also to catch any possible fluctuations in their trend produced by environmental factors [9-12].

In the last decades, many authors have investigated the correlation between damage and dynamic parameters' variation, eventually finding different modal-based damage indexes [13-16]. Damage Identification (DI) is a process of increasing complexity that entails four main levels: Detection, Localization, Assessment and Prediction. This type of grouping was used for the first time by Ritter [17]. In order to achieve a higher level of identification, it is necessary that the previous level is guaranted. Thus, the process implies a greater difficulty, both in computational terms and amount of data required, as it aims for higher accuracy.

While the existence of damage (Detection) can be assessed by tracking the frequency values estimated from the vibration signals measured just by a reduced number of sensors, additional modal parameters like mode shapes are necessary to infer the position of damage (Localization), thereby a higher sensor density is demanded. Moreover, when frequency drops are considered, it is essential to get rid of possible temperature and humidity effects which can mask changes due to damage. Their influence can be removed using appropriate statistical tools applied to the recorded data $[18,19]$. The greater difficulty for the third level of DI (Assessment) lies in the necessity of 
accurate benchmark studies of similar elements/structures showing analogous vulnerabilities to far as the last level of DI is concerned, the complexity of the identification process increases owing to the need of analytical models that take into account the actual state of the structure as well as of probabilistic models representative of the evolution of the structural behavior considering the most likely damages that might occur.

The first applications of DI techniques were on steel and RC elements [20-23]. However, the last decade has been marked by an increasing interest to extend their applicability to masonry constructions $[4,10,11,19,24-26]$. The majority of studies conducted on real structures focused their attention on Level 1 DI methods, given the difficulties to perform extensive controlled testing campaigns and the consequent uncertainties for the application of higher level DI methods. Laboratory tests can provide great advantages in this regard, allowing to acquire a larger and replicable number of measurements in controlled environmental conditions for testing and validating even high-level DI methods.

The aim of this work is to enrich the database of vibration-based damage identification methods (VBDIMs) for masonry structures, with focus on arched systems, by elaborating a modalbased index able to infer not only the presence of damage (Level 1), but also to provide a quantification of its extent (Level 3). Arches and vaults were widely used in the past for their capacity to cover large spans and resist to high compression loads; they can be found indeed in many of monumental constructions and historical masonry bridges. Damage identification techniques suitable for this type of structural systems have been debated by some authors with numerical and experimental analyses that showed satisfactory results [27-32]; however, most of the methods presented might ultimately result too complex to be employed in the common engineering practice, mainly because of the high number of sensors required to achieve a good accuracy.

This research shares the same context, with the aim to find an index that allows to globally identify and quantify the damage in masonry arches, but using only a few sensors. The main features distinguishing the proposed index from the others available in the literature are the simplicity of its formulation and the replicability, even by users without specific knowledge in the field. The procedure is here applied to six reduced-scale masonry models tested in controlled environmental conditions, although the final goal is to upgrade this formulation to be exploited for full-scale structures. Based on Operation Modal Analysis (OMA), the proposed index resorts to frequency shifts between progressive displacement scenarios to detect the damage and to assess the consequent global stiffness degradation induced by it. Although not able to localize the damage in spatial terms, the index results a meaningful indicator to define baseline information about this type of structural systems and set threshold performance values beyond which reinforcement interventions are necessary.

The data used to elaborate and validate the damage index were collected during pseudo-static displacement-controlled experiments on six adobe arches carried out at the Structural Laboratory of the Civil Engineering Department of the University of Minho (Portugal) [33]. The geometry of the specimens and the testing campaign are described in Section 2, where the Ambient Vibration Tests (AVTs) performed after each induced damage scenario to track the frequency variation are also detailed. Section 3 presents the formulation of the damage index, demonstrating its direct relationship with the stiffness degradation of the arches obtained from the analysis of the experimental force-displacement curves. Finally, to verify the replicability and wide applicability of the proposed damage index, several numerical non-linear static analyses are performed and 
discussed in Section 4, taking into account different types of arch collapse mechanisms. The

\section{Experimental Tests}

\subsection{Description of the specimens and testing procedure}

In order to investigate the behavior of adobe arches under increasing vertical loading and progressive damage scenarios, six 1:3 scaled specimens of the typical arches found in the houses of the historical city of Yazd (central Iran) [33,34] were built and tested in the Structural Laboratory of the University of Minho (Guimarães, Portugal) [35]. Each arch was constructed using about 473 scaled adobe bricks of dimensions $90 \times 65 \times 20 \mathrm{~mm}^{3}$ (height $\times$ width $\times$ thickness), produced in the laboratory and laid vertically with earthen mortar following a running bond pattern, keeping the joints' thickness less than $6 \mathrm{~mm}$. This type of construction, where units are laid vertically to the circumferential courses, was dominant in middle-east countries as Iran and Egypt. The arches were supported by concrete abutments fixed to the laboratory floor by steel rods and bolts. The geometry of the scaled arches and the test layout are illustrated in Figure 1.

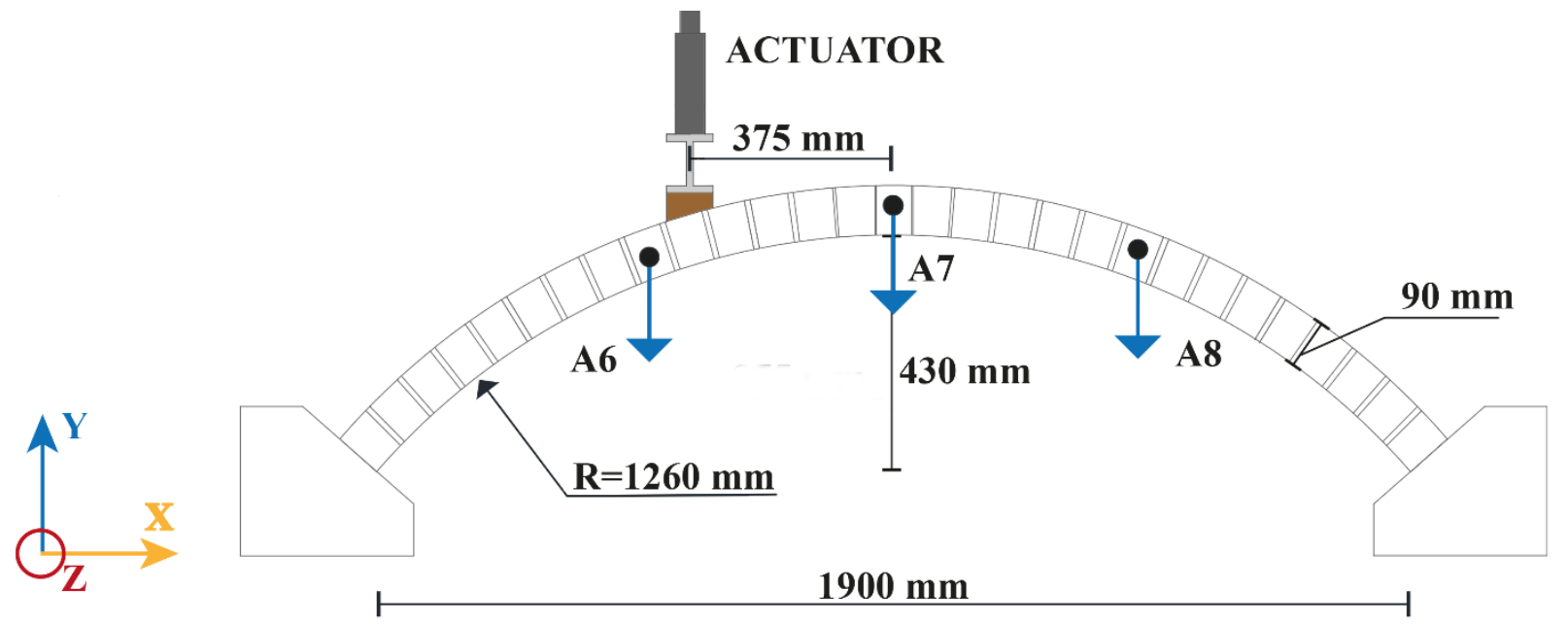

a)

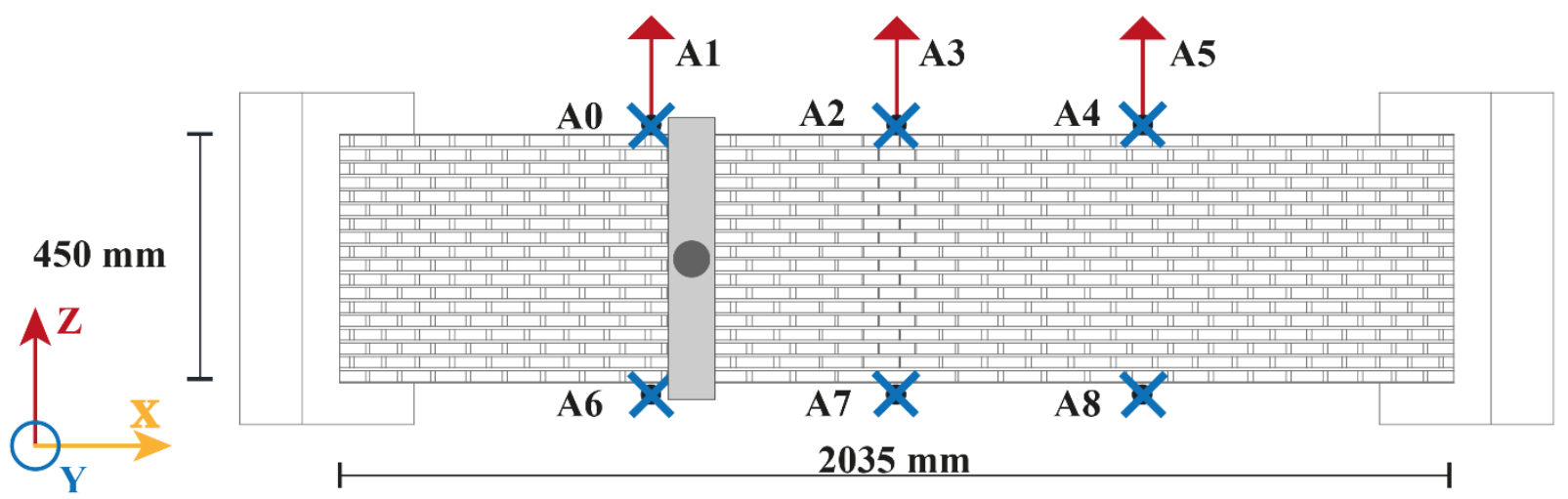

b)

Figure 1 Geometric dimensions of the adobe arches and test layout with sensors location: a) Front view; b) Top view.

Four out of six arches were reinforced with a glass Textile Reinforced Mortar (TRM) covered with earth-based mortar, aiming at testing the effectiveness of this relatively-recent affordable strengthening solution to improve the overall structural capacity of adobe arches. Specifically, two arches were strengthened with the TRM at the intrados and two other arches were reinforced with this same material at the extrados. In the intrados TRM application, four spike connectors were 
added to prevent the early detachment. After the pseudo-static tests, the unreinforced adobe arches were repaired by means of clay-based grout injections to restore the continuity of the material and then reinforced with TRM at the intrados, in order to check the effectiveness of the repairing method on previously damaged elements. The arches were subjected to loading-unloading cycles until collapse, except for the UN arches' tests that were stopped before to be able to repair and reinforce them, and to perform further tests. The number of cycles applied to each arch is reported in Table 1, where it is possible to observe a slightly different behavior for SE1 and SE2 arches, related to a distinct collapse: the former due to delamination, the latter due to rupture of the fiberglass.

Table 1 List of tests performed on the six adobe arches with their relative acronyms. [35]

\begin{tabular}{lcc}
\hline \multicolumn{1}{c}{ Arch Type } & Test Acronym & No. Cycles \\
\hline Unreinforced & UN (1-2) & 8 \\
Strengthened at the Extrados & SE (1-2) & $12($ SE1), 14(SE2) \\
Strengthened at the Intrados & SI (1-2) & 10 \\
Repaired and Strengthened at the Intrados & RSI (1-2) & 10 \\
\hline
\end{tabular}

The pseudo-static tests were carried out by applying controlled displacements, by stages of increasing amplitude, at the arch third span through a hydraulic jack. To prevent a concentrated application point, the displacement-imposition system consisted of a steel beam connected to a wooden beam shaped according to the arch curvature. The displacements were applied in progressive stages in order to reach different Damage Scenarios (DSs). Table 2 shows the displacement rate imposed at each cycle together with the loading and unloading velocities used during the tests for each damage scenario.

Table 2 Summary of displacement rates and velocities adopted for the pseudo-static tests. [35]

\begin{tabular}{cccc}
\hline Cycle & $\begin{array}{c}\text { Maximum displacement } \\
{[\mathbf{m m}]}\end{array}$ & $\begin{array}{c}\text { Loading speed } \\
{[\mathbf{m m} / \mathbf{s}]}\end{array}$ & $\begin{array}{c}\text { Unloading speed } \\
{[\mathbf{m m} / \mathbf{s}]}\end{array}$ \\
\hline DS 1 & 0.48 & 10 & 10 \\
DS 2 & 0.62 & 10 & 10 \\
DS 3 & 0.80 & 10 & 10 \\
DS 4 & 1.18 & 10 & 10 \\
DS 5 & 4 & 10 & 30 \\
DS 6 & 6 & 10 & 30 \\
DS 7 & 8 & 10 & 50 \\
DS 8 & 10 & 10 & 50 \\
DS 9 & 14 & 10 & 50 \\
DS 10 & 18 & 15 & 50 \\
DS 11 & 22 & 15 & 50 \\
DS 12 & 26 & 15 & 50 \\
DS 13 & 34 & 15 & 50 \\
DS 14 & 42 & 15 & 50 \\
\hline
\end{tabular}

\subsection{Testing campaign and results}

\subsubsection{Pseudo-static tests}

A series of pseudo-static loading-uloading cycles were progressively applied to induce damage in the arches. During the tests, the reaction forces corresponding to the imposed displacements were recorded using the $10 \mathrm{kN}$ load cell of the actuator. Moreover, eight Linear Variable Displacement 
Transducers (LVDTs) were deployed to measure each arch's displacements at relevant locations. A detailed description of these instrumentation of the arches is out of the scope of this paper; further information in this regard is provided in [35] and [33]. The force-displacement curves presented and discussed hereafter refer to the data monitored at third-span by the LVDT and load cell operating simultaneously on the hydraulic jack.

Before starting with the tests, the arches were pre-stressed, placing two cement bags of $25 \mathrm{~kg}$ each at midspan. The loading-unloading cycles were applied consecutively until the collapse condition was reached, except for the unreinforced arches UN 1 and UN 2, whose tests were stopped once a $20 \%$ decrease of the maximum force was recorded, thereby limiting the visible induced damage and facilitating their repair by means of TRM at the intrados.

The outcome of the pseudo-static tests conducted on each arch is plotted in Figure 2 in terms of force-displacement capacity curves. For comparison purposes with the UN arches, two quantities are computed for each group, namely the average maximum force and the average ductility, where the latter is calculated as the ratio between the displacement recorded in correspondence of the maximum force and the displacement measured upon reaching in the following cycles $80 \%$ reduction of the maximum force [36]. Observing the curves, it is clear that the application of TRM at the extrados of the undamaged adobe arches appears to be the best technique to increase both the ductility and structural resistance. In fact, an increase of about 395\% (29.98 SE vs. 6.05 UN) and $130 \%(2.67 \mathrm{kN} \mathrm{SE}$ vs. $1.16 \mathrm{kN} \mathrm{UN})$ is observed in terms of ductility and maximum force, respectively, as compared to the UN specimens. On the other hand, the application of the TRM reinforcement at the intrados of the arches leads to a decrease of ductility equal to $49 \%$ (3.63 SI vs. $6.05 \mathrm{UN})$, but proves to be effective to increase the load capacity of about $118 \%(2.53 \mathrm{kN}$ SI vs. $1.16 \mathrm{kN} \mathrm{UN})$. In what concerns the arches previously damaged and then reinforced with TRM at the intrados, their capacity curves show the smallest increase in terms of resistance, around $27 \%$ as compared to its unreinforced configuration (1.48kN RSI vs. $1.16 \mathrm{kN} \mathrm{UN})$, and a $90 \%$ decrease in ductility (0.59 RSI vs. $6.05 \mathrm{UN}$ ). The different increment of resistance between SI and RSI arches is due to the lack of perfect continuity of the material after cracking appears. For a thorough analysis of the strengthening capabilities provided by the TRM reinforcement, the reader is referred to [3335]. As far as this work is concerned, only the results reported above are of interest for the comprehension of the damage index presented next. 
1

2

3

4

5

6

7

8

9
10

11

12

13

14

15

16

17

18

19

20

21

22

23

24

25

26

27

28

29

30

31

32

33

34

35

36

37

38

39

40

41

42

43

44

45

46

47

48

49

50

51

52

53

54

55

56

57

58

59

60

61

62

63

64

65
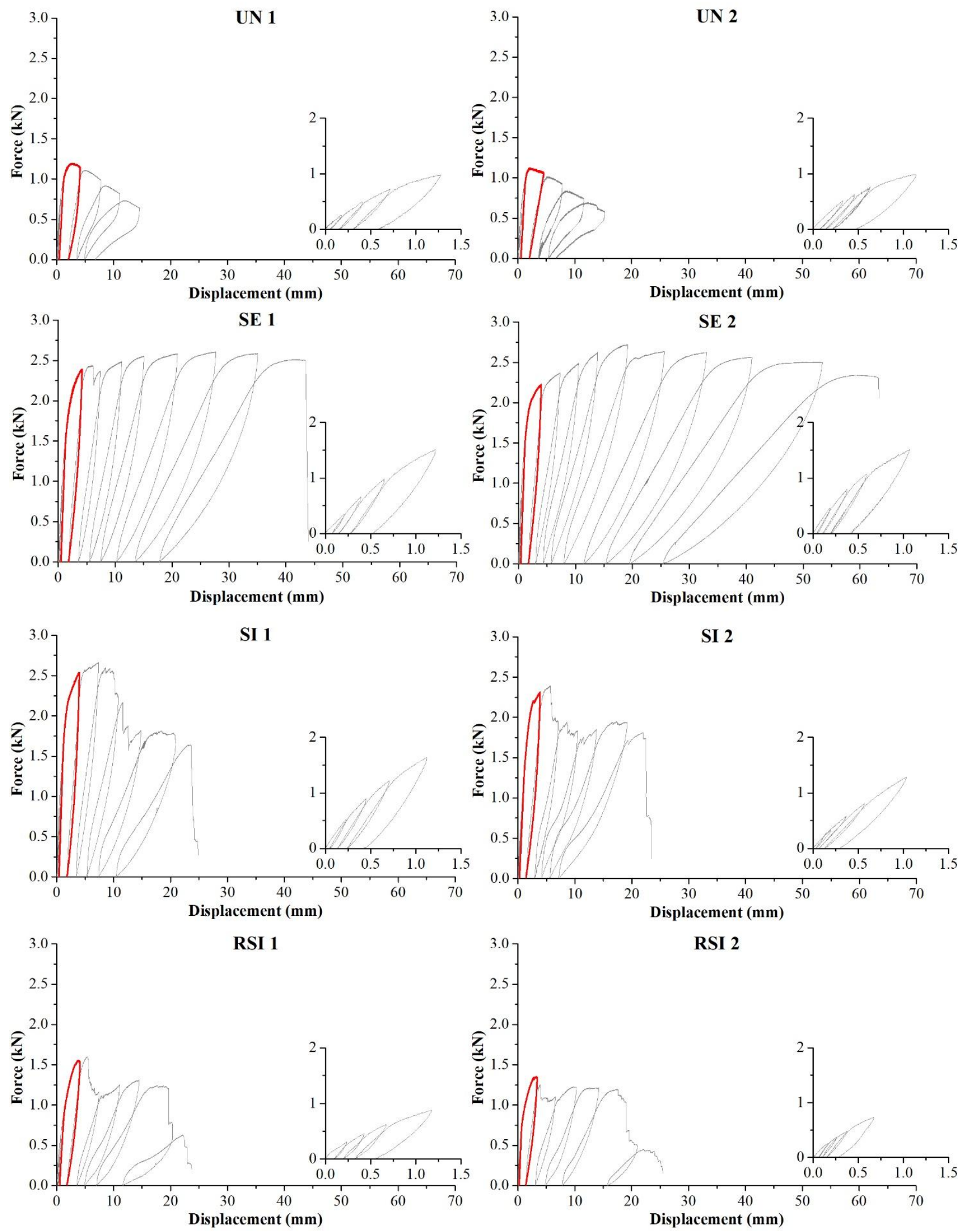
Figure 2 Force-displacement curves obtained from the pseudo-static tests per each arch analysed (in red the fifth cycle that corresponds to the first visible cracks). A close-up of the first four cycles is provided on the right.

For all the tested samples, regardless of the presence of the reinforcement, the first cracks became visible during damage scenario DS 5 (Figure 2, red lines) for an imposed displacement of 4 $\mathrm{mm}$, even though the maximum force attained in this cycle did not always correspond to the maximum resistance of the arch. Nevertheless, the force-displacement curves show a clear nonlinear behavior since the first cycles (Figure 2), meaning that micro-cracks still not visible to the naked eye had already developed. The crack pattern after DS 5 varied in each arch according to the presence and position of the TRM (Figure 3). In the unreinforced arches UN 1 and UN 2, four and three cracks appeared (Figure 3a-b), respectively, proving their very low resistance against imposed vertical displacements. As for the strengthened arches SE (1-2) and SI (1-2), only a single crack opened after DS 5: at the intrados, in correspondence of the displacement-imposition system, for the arch reinforced at the extrados (Figure 3c-d), and at the extrados, symmetrically opposite to the displacement application point, for the arch strengthened at the intrados (Figure 3e-f). The variation of the position of the crack hinges depends clearly on to the different reinforcement solutions adopted. Finally, in regard to the repaired and strengthened aches RSI 1 and RSI 2, the first visible cracks after DS 5 varied in number and location, probably because of the inherent difficulties in performing identical repairs in the two samples, but also because of the imperfections typical of manually assembled geometries. Indeed, a slight difference in the number of cracks was already evident in the corresponding unstrengthened models. However, it is noted that none of the RSI arches showed cracks in correspondence of the displacement-imposition system given the presence of the TRM (Figure 3g-h).
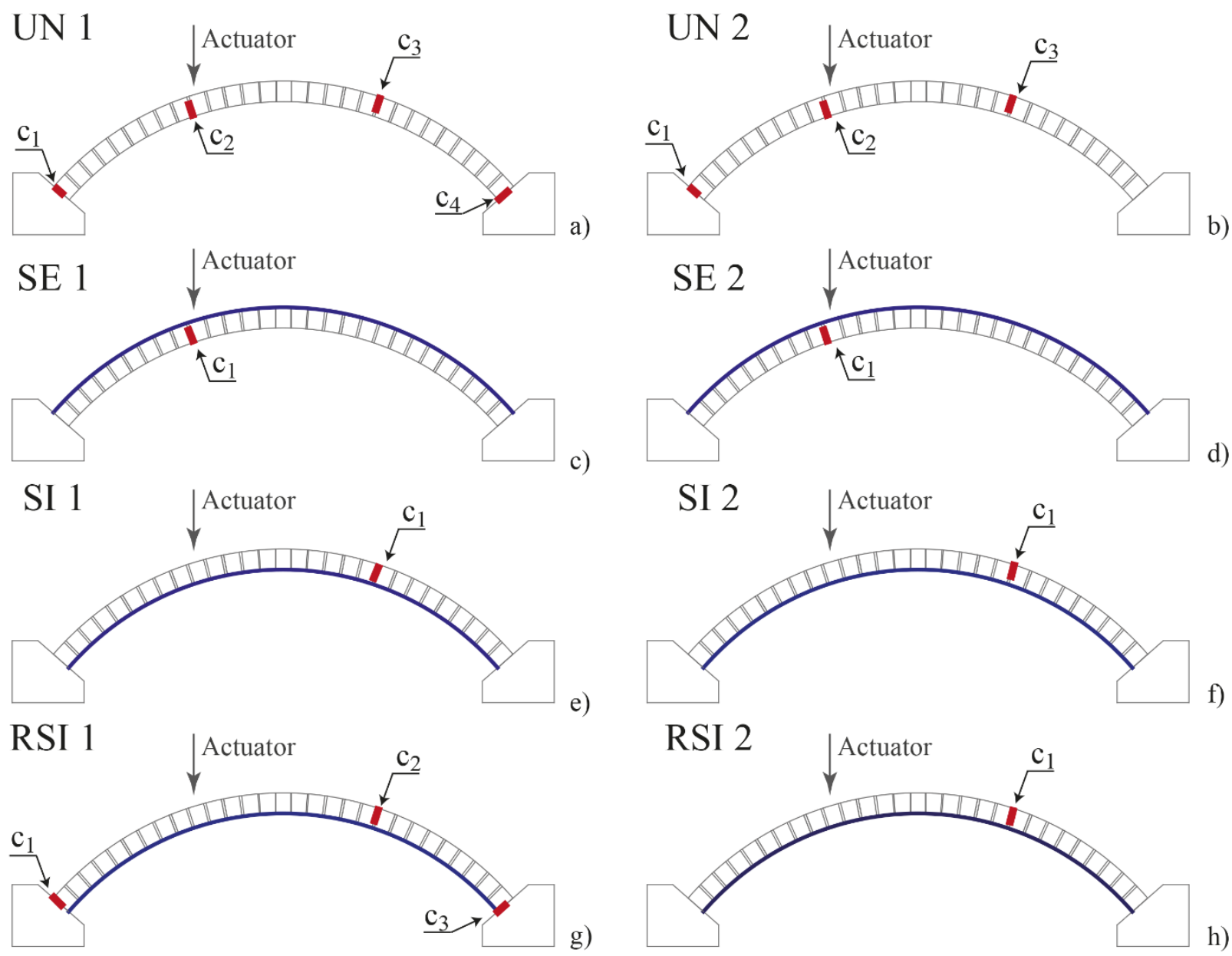
Figure 3 First visible cracks for each testd arch (the number to identify the cracks does not correspond to their sequence of occurrence):a) Unreinforced; b) Reinforced at the extrados; c) Reinforced at the intrados; d) Repaired and reinforced at the intrados.

As the displacements increased, all adobe arches, with the exception of UN 1 and UN 2 (four hinges), developed a three-hinge collapse mechanism. In particular, the reinforced arches collapsed following the detachment of the fiber textile (Figure 4).
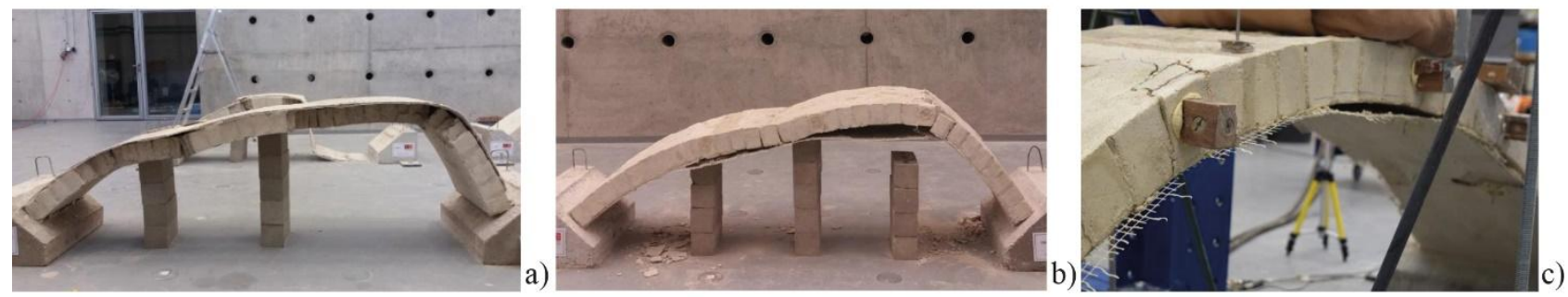

Figure 4 Collapse due to the TRM detachment: a) arch strengthened at the extrados (SE1); b) arch strengthened at the intrados (SI1); c) Repaired arch strengthened at the intrados (RSI1).

\subsubsection{Dynamic identification tests}

Before starting with the pseudo-static tests and at the end of each displacement cycle, dynamic identifications tests were carried out with the aim of following the evolution of the modal response of the arches and recording any possible change in their dynamic properties as the damage developed. Nine uniaxial piezoelectric accelerometers (model PCB 393B12), with a sensitivity of $10 \mathrm{~V} / \mathrm{g}$, a dynamic range of $\pm 0.5 \mathrm{~g}$ and a bandwidth ranging from $0.15 \mathrm{~Hz}$ to $1000 \mathrm{~Hz}$, were used to acquire in one setup the time-dependent responses of six measurement points, for a total of nine degrees of freedom (DOFs): six sensors were placed along the back edge of the arch, three in vertical direction $(\mathrm{Y})$ and three in horizontal direction $(\mathrm{X})$, and three sensors were positioned along the front edge of the arch in vertical direction (Figure 1). The sensors were distributed where the modal curvature usually assume their maximum values.

The acquisitions were made using ambient noise as a source of excitation, being this the most common technique employed nowadays for the dynamic characterization of in-situ and laboratory structures, given the relatively low cost of the equipment and the possibility to perform the tests during the actual operational conditions of the structure. As for the present case, the ambient vibration tests were performed in laboratory environment, thus with controlled background noise and constant temperature-humidity conditions. The response signals were acquired with a sampling frequency of $400 \mathrm{~Hz}$ through a multichannel data acquisition system provided with a 24-bit ADC and anti-aliasing filters, and connected by cables to the accelerometers. Each acquisition lasted 20 minutes, providing acceleration time-series longer than 2000 times the period of each arch's fundamental mode.

The recorded signals were then processed and analysed using the ARTeMIS software [37] by means of a time-domain output-only modal identification technique: the Stochastic Subspace Identification with Unweighted Principal Component (SSI-UPC) [38]. For all the analyzed arches, three vibration modes in the frequency range $20-40 \mathrm{~Hz}$ were unequivocally identified in the undamaged condition: one dominant out-of-plane bending mode ( $Z$ direction) and two vertical bending modes (Y direction), of which one asymmetrical and one nearly-symmetrical (Figure 5). 
MODE 1

Out-of-plane bending

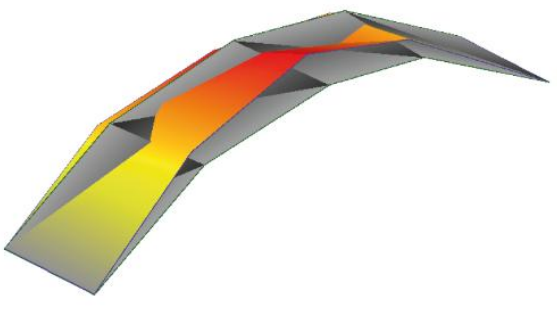

MODE 2

Vertical asymmetrical bending

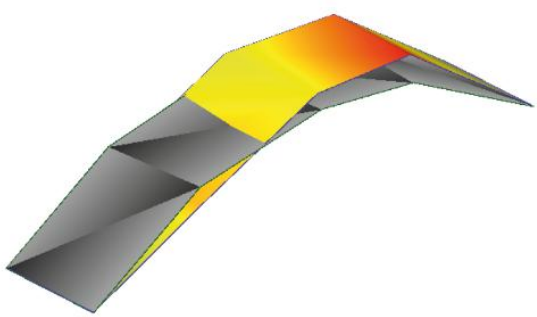

MODE 3

Vertical almost symmetrical bending

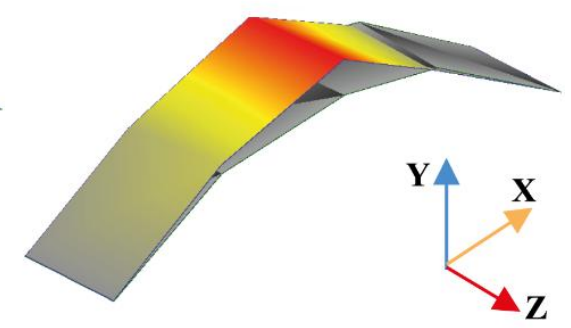

Figure 5 First three typical mode shapes of the adobe arches in their undamaged condition (in grey the undeformed shape).

The first three frequencies estimated for the Reference Scenario (RS; undamaged) of each specimen are reported in Table 3. By observing their values, it is possible to notice that, despite of the direct relationship between stiffness and frequency, the introduction of the TRM reinforcement has very little or null influence on the first modal frequency, being this frequency associated with an out-of-plane bending mode shape; on the contrary, a beneficial effect is remarked as far as the frequencies of the second and third modes are concerned, when the TRM is applied on the intrados surface of the arch. The highest variations on the frequencies occur to the RSI 2 (repaired and strengthened arch).

Table 3 Frequencies of the first three vibration modes estimated for all adobe arches in their undamaged condition.

\begin{tabular}{lcccccccc}
\hline & \multicolumn{1}{c}{ Frequency [Hz] } \\
& UN 1 & UN 2 & SE 1 & SE 2 & SI 1 & SI 2 & RSI 1 & RSI 2 \\
\hline MODE 1 & 23.97 & 24.27 & 23.32 & 23.15 & 23.58 & 23.50 & 24.27 & 21.97 \\
MODE 2 & 29.74 & 28.99 & 28.98 & 29.68 & 31.38 & 31.42 & 30.47 & 31.37 \\
MODE 3 & 36.49 & 34.82 & 34.30 & 34.35 & 36.46 & 37.86 & 38.82 & 34.39 \\
\hline
\end{tabular}

The mode shapes identified in the undamaged condition were taken as references for the identification of the first three dominant vibration modes in the subsequent scenarios. The Modal Assurance Criterion (MAC) [38] between compatible modes of the damaged and subsequent undamaged conditions was used as statistical indicator to assess the degree of similary of the candidate modal vectors. This allows to identify the actual corresponding vibration modes between different scenarios based on the highest MAC value, according to the well-know formulation:

$$
\operatorname{MAC}\left(\left\{\varphi_{\mathrm{RS}}\right\},\left\{\varphi_{\mathrm{DS}}\right\}\right)=\frac{\left|\left\{\varphi_{\mathrm{i}, \mathrm{RS}}\right\}^{\mathrm{T}}\left\{\varphi_{\mathrm{i}, \mathrm{DS}}\right\}\right|^{2}}{\left(\left\{\varphi_{\mathrm{i}, \mathrm{RS}}\right\}^{\mathrm{T}}\left\{\varphi_{\mathrm{i}, \mathrm{RS}}\right\}\right)\left(\left\{\varphi_{\mathrm{i}, \mathrm{DS}}\right\}^{\mathrm{T}}\left\{\varphi_{\mathrm{i}, \mathrm{DS}}\right\}\right)}
$$

where $\varphi_{i, R S}$ and $\varphi_{i, D S}$ indicate the mode shape vectors of the $i$-th mode of the reference and damaged condition, respectively. This led to obtain a consistent comparison in terms of estimated frequency decay among consecutive damage scenarios. A visual insight into the frequency changes induced by the stiffness degradation of the adobe arches with progressive damage is provided in Figure 6. 
MODE 1
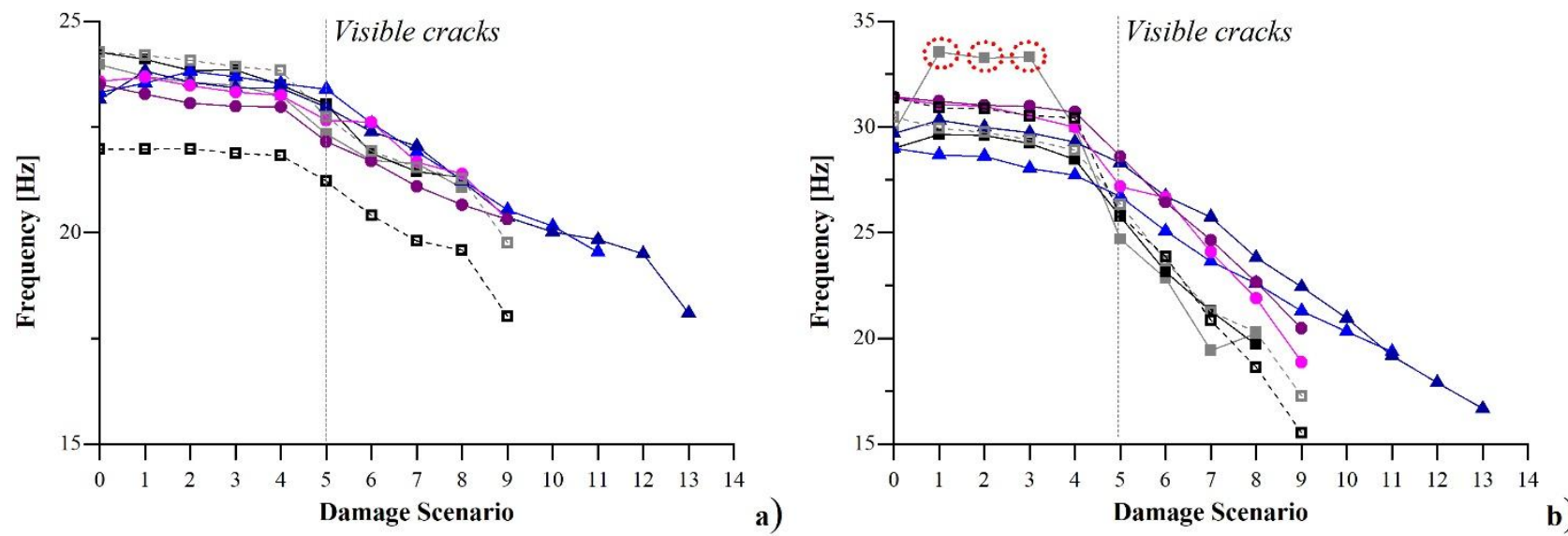

MODE 3

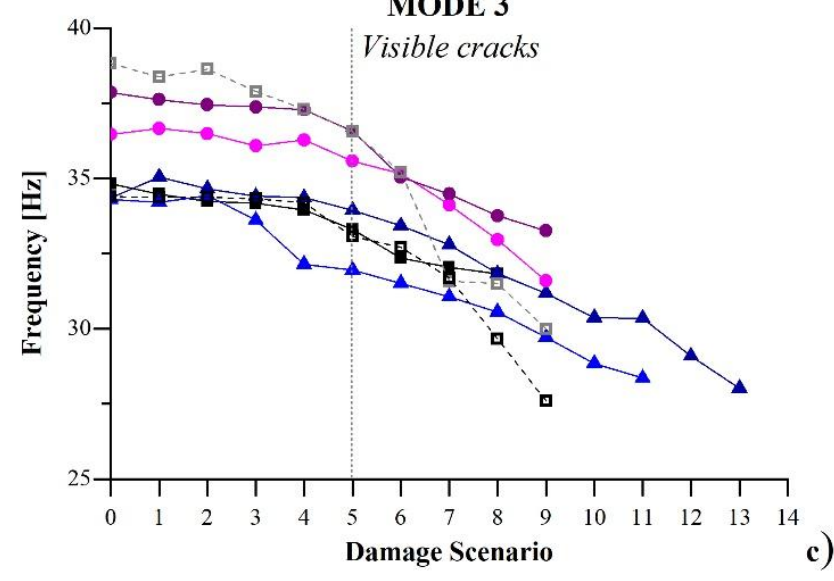

Figure 6 Frequencies variation over progressive damage scenarios. Due to the collapse, the frequencies of DS 14 have not been recorded.

As expected, the frequencies of all three identified modes tend to decrease as the damage increases; their average variations, considering all arch types, are: $16 \%$ for the $1^{\text {st }}$ and $3^{\text {rd }}$ mode, and $39 \%$ for the $2^{\text {nd }}$ mode. Unexpected $11 \%$ frequency increments are observed for the $2^{\text {nd }}$ mode of arch UN 1 during the first three DSs, probably cause to an initial compaction at the joints (earthen mortar). For this reason, the three values circled in red in Figure 6-b will not be considered in this study. Comparing the frequency drops of all three modes, it is evident how the most significant downshifts are recorded for mode 2, i.e. the asymmetrical vertical bending mode, which is therefore assumed as the most representative of the damage evolution in all arch typologies $(47 \%$ decrease for UN 1, 51\% for UN 2, 50\% for SE 1, 66\% for SE 2, 66\% for SI 1, 54\% for SI 2, 77\% for RSI 1 and $102 \%$ for RSI 2). In fact, following DS 5, that is the scenario in which the first visible cracks were detected, mode 2 results to be the one suffering the most abrupt variation in the frequency slope (the average reduction with respect to DS 4 is of $8 \%$, against the $3 \%$ and $1 \%$ of modes 1 and 3). Even though the SI specimens featured higher frequency values for the same mode in the initial scenarios, the arches showing the highest frequencies at the end of the experimental campaign are those with extrados reinforcement (SE, light and dark blue lines in Figure 6). The $2^{\text {nd }}$ mode of the SI arches (see purple and pink curves) shows a sudden change passing from DS 4 to DS 5, becoming parallel to UN arches (black and gray filled curves). The decrease of the stiffness is directly associated with the sudden damage occurred at the interface with the intrados reinforcement due to the high radial stresses, quickly leading to the condition of UN arches. These results are in agreement with the force-displacement curves obtained from the pseudo-static tests (see Section 
2.2.1), confirming the efficacy of the TRM strengthening solution when applied to the extrados of arched structures.

\section{Development of simplified damage indicators}

\subsection{Stiffness loss based on experimental tests}

The reduction in frequencies during the experimental campaign was a clear indication of the presence of damage. Indeed, as widely known, if controlled environmental conditions are guaranteed, frequency changes may be associated either to mass or stiffness variations. In what concerns the adobe arches, the observed frequency downshifts are directly related to the loss of stiffness, since no mass variation did occur during the tests. Therefore, starting from the capacity curves discussed in Section 2.2.1, different types of tangent and secant stiffnesses are calculated and compared, in order to find the most appropriate description of the decreasing arch capability and assess the seriousness of the damage. They are the tangent stiffness $K_{\mathrm{BS}}$ evaluated according to the BS 1881-121:1983 [39]; the tangent stiffness $K_{\text {ASTM }}$ calculated according to the ASTM C469/C469M [40]; the loading secant stiffness $K_{\text {load }}$; the unloading secant stiffness $K_{\text {unload }}$ [41]; and the secant stiffness $K_{\text {sec }}$ passing through the origin (condition of zero force and zero displacement) and the point corresponding to the maximum force in each following cycle. Figure $7 \mathrm{a}$ illustrates how each slope has been determined.

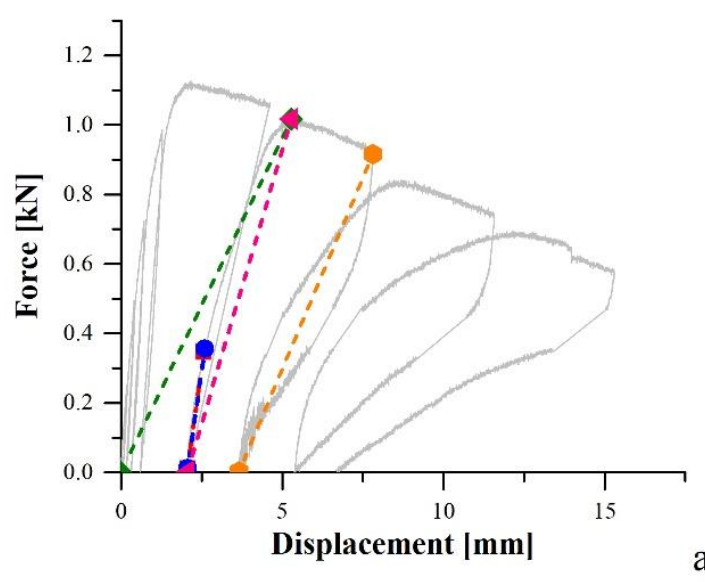

a)

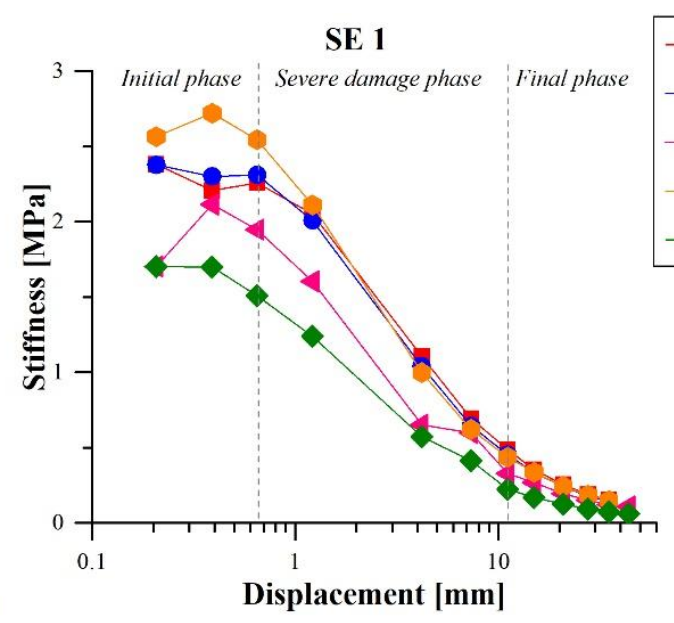

Figure 7 Stiffness loss analysis: a) graphical description of the evaluation of each type of stiffness; b) stiffness decrease for SE1 arch during the pseudo-static tests.

As an example, Figure $7 \mathrm{~b}$ shows for arch SE 1 the trend of all considered stiffnesses as a function of the imposed displacements. From this comparison, it is possible to observe that only the tangent stiffnesses $K_{\mathrm{BS}}$ and $K_{\mathrm{ASTM}}$ provide a consistent description of the damage evolution, since three clear phases can be distinguished: i) stable initial phase, where even if hidden cracks occur these are not soundly affecting the overall arch stiffness; ii) severe damage phase, corresponding to the appearance of visible cracks and a clear stiffness loss; iii) stable final phase, when crack hinges are well formed, the stiffness tends to zero and the arch resists only for static equilibrium. Since the tangent stiffnesses calculated with the two methodologies were very similar, only $K_{\mathrm{ASTM}}$ was used for the subsequent evaluations.

\subsection{Correlation between stiffness and frequency variation}

The following Section presents the formulation of a new damage index for arched systems able to reproduce the progressive stiffness reduction using only the frequency variation. 


\subsubsection{Formulation of the damage index}

In general terms, the stiffness $K_{d}$ of a damaged structure can be defined as a function of a scalar degradation parameter $D_{k}$, which represents the reduction of stiffness with respect to its initial value $K_{0}$, i.e. the stiffness of the undamaged structure as also reported in [42]:

$$
\begin{gathered}
K_{d}=\left(1-D_{k}\right) K_{0} \\
D_{k}=1-K_{d} / K_{0}
\end{gathered}
$$

The damage identification method hereafter applied stems from the observation that the damage scenarios induced during the testing campaign mainly affected the bending behavior of the arches. As a result, the bending stiffness turns to be the key parameter for the estimation of the damage degree.

Let us consider a geometrically planar beam, i.e. a beam whose undeformed axis is assumed to be a circle lying on the plane of the beam, in order to have a constant, unique curvature. The cross section is assumed constant and with the same orientation with respect to the plane of the beam.

In the curved beam the action of a planar bending produces a variation of curvature, passing from an initial value $k_{i}=1 / R_{i}$ to a final one $k_{f}=1 / R_{f}$, satisfying the classical Euler-Bernoulli hypothesis. Considering a generic fibre at distance $y$ with respect to the neutral axis, the strain along the $x$-beam is:

$$
\varepsilon_{x}=\frac{1_{f}-l_{i}}{l_{i}}=\frac{\left(R_{f}+y\right) d \beta_{f}-\left(R_{i}+y\right) d \beta_{i}}{\left(R_{i}+y\right) d \beta_{i}}=\left(k_{f}-k_{i}\right) \frac{y}{1+k_{i} y}
$$

where $d \beta_{i}$ and $d \beta_{f}$ are the angle at the center in the initial and final configurations, and at the neutral axis $R_{i} d \beta_{i}=R_{f} d \beta_{f}$. The bending moment is equal to:

$$
\mathrm{M}_{\mathrm{z}}=\int_{\mathrm{A}} \sigma_{\mathrm{x}} \mathrm{y} \mathrm{dA}=\mathrm{E}\left(\mathrm{k}_{\mathrm{f}}-\mathrm{k}_{\mathrm{i}}\right) \int_{A} \frac{\mathrm{y}^{2}}{1+\mathrm{k}_{\mathrm{i}} \mathrm{y}} \mathrm{dA}
$$

and the constitutive law for a bending curved beam is:

$$
\left(\mathrm{k}_{\mathrm{f}}-\mathrm{k}_{\mathrm{i}}\right)=\frac{\mathrm{M}_{\mathrm{z}}}{\mathrm{EJ}_{\mathrm{z}}} \text { where } \mathrm{J}_{\mathrm{z}}=\int_{\mathrm{A}} \frac{\mathrm{y}^{2}}{1+\mathrm{k}_{\mathrm{i}} \mathrm{y}} \mathrm{dA}
$$

In the case of a beam with weak curvature the, term $k_{i} y$ is negligible; the neutral axis is centroidal and the classical Navier formula is still valid [43]. Therefore, the bending stiffness $(K)$ is comparable to that of a straight beam. In the initial phase, the stress state induced by the bending moment varies linearly along the thickness of the arch, $t$, reading the maximum stress values at the top and bottom edges. When the tensile strength of the material is reached, cracks start to occur; assuming damage as a linear perturbation, it can be described as a cross-section loss of the area moment of inertia due to a reduction of the arch thickness (materials and boundary conditions being unvaried). Thus, from the equations above it is deduced that the scalar degradation parameter $D_{k}$ depends on the thickness variation between the $i$-th damage scenario $\left(t_{i}\right)$ and the reference scenario $\left(t_{0}\right)$, resulting a variation of cubic order: 
and replacing Eq. ( 8 ) into Eq. ( 7 ), the following index $D_{f}$ has been defined for assessing the structural damage:

$$
\mathrm{D}_{f}=1-\left(\frac{f_{\mathrm{j}, \mathrm{i}}}{f_{\mathrm{j}, 0}}\right)^{6}
$$

where $f_{j, i}$ and $f_{j, 0}$ are the frequency values corresponding to the $j$-th mode in the considered damaged and undamaged configurations, respectively. It is noted that this is a practical formulation aimed at simplifying the evaluation of the damage degree in masonry arches, and its efficiency is validated through experimental (Section 3.1) and numerical results (Section 4).

\subsubsection{Stiffness-based vs. frequency-based damage index}

With the purpose of assessing the consistency of the formulation illustrated above and its agreement with the experimental results, the frequency-based damage index $D_{f}$ introduced in Eq. (8) is computed for the second experimental mode (vertical asymmetrical bending) in progressive stages for all the adobe arches and compared with the damage parameter $D_{k}$ of Eq. (3), in which the stiffness of the arch for the damaged and undamaged conditions is calculated according to the ASTM standards [40], considering as $K_{0}$ the tangent stiffness of the first loading branch of the test and as $K_{d}$ the tangent stiffness estimated in the loading branch of the cycle following the DS under consideration. The results are shown in Figure 8, where the percentage variation of both damage factors $\left(D_{k}, D_{f}\right)$ is represented over progressive scenarios.

Observing the trend of $D_{k}$, which is inversely related to $K_{d}$, it is noted that in the initial stages there is an increase in terms of stiffness, likely generated by the material type that tends to compact [42]. Afterwards, the stiffness gradually decreases up to reaching the first visible cracks, when the slope changes abruptly. In the final phase, corresponding to the last equilibrium condition, the stiffness variation stabilizes, reading the highest damage percentage value. As previously mentioned, this last stability phase is less evident in the unreinforced arches (UN 1-2) because the tests were stopped before collapse in order to repair the models. By comparing the curves of the SE and SI arches, the latter's shows a greater slope in the final phase, confirming the less effectiveness of this strengthening solution as compared to the former's. However, it is interesting to note that in almost all cases the first visible cracks occur when the stiffness-based damage factor $D_{k}$ exceeds the threshold value of 50\%, in agreement with what reported by Kubica [44].

By inspecting the trend of $D_{f}$, it is evident how the new index is able to consistently follow the stiffness degradation process affecting the arches. The percentage difference between $D_{f}$ and $D_{k}$ becomes smaller and smaller as the damage severity increases and cracks become visible, tending to $0 \%$ towards the last displacement cycles, with the exception of arch SE 2 and UN 1 that display anomalous values for DS 5 and DSs 1-2-3, respectively. On the contrary, the difference between the two indices is higher before visible damage, especially in the arches where the initial compaction was more remarkable. It seems that this effect is not caught by the frequencies in the early stages, since they do not increase, except for SE 2. 
UN1

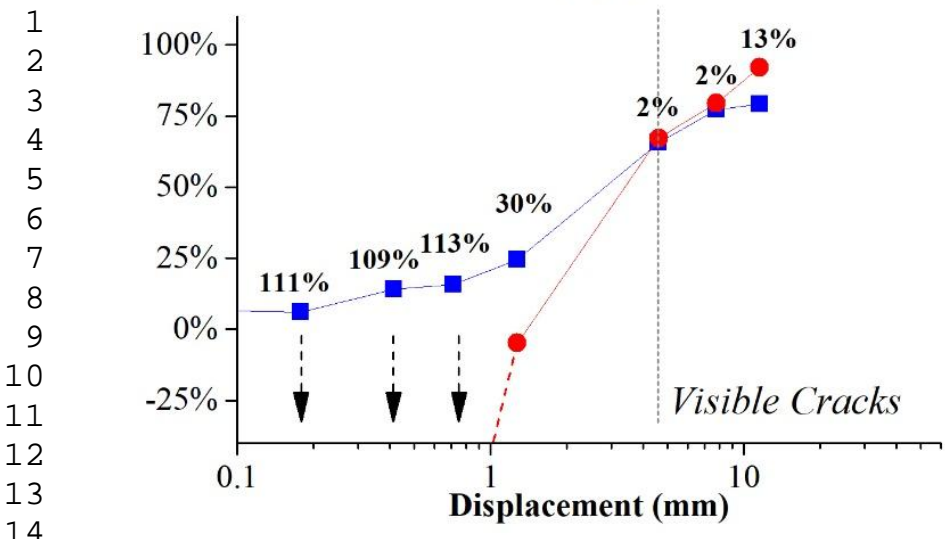

SE1

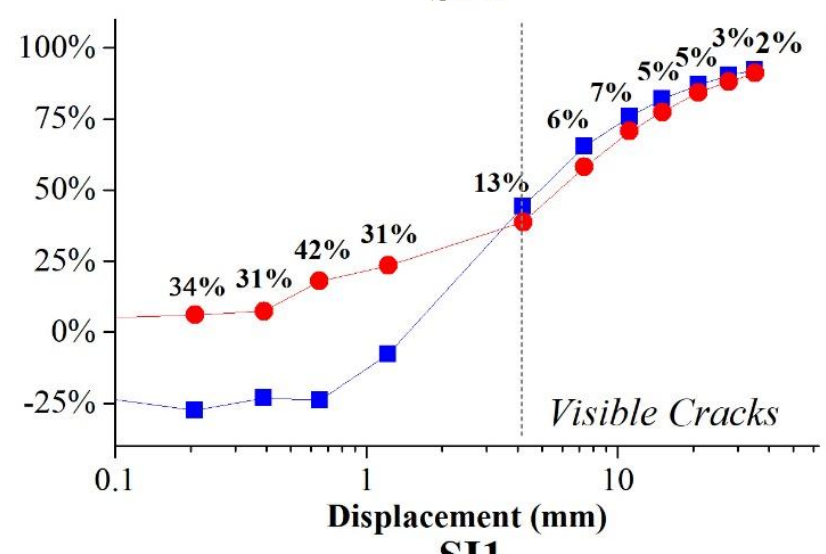

SI1

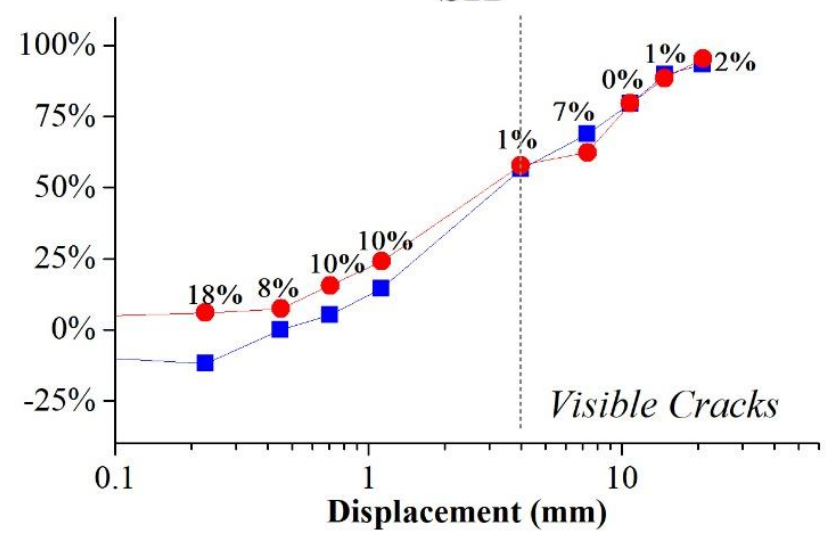

RSI1

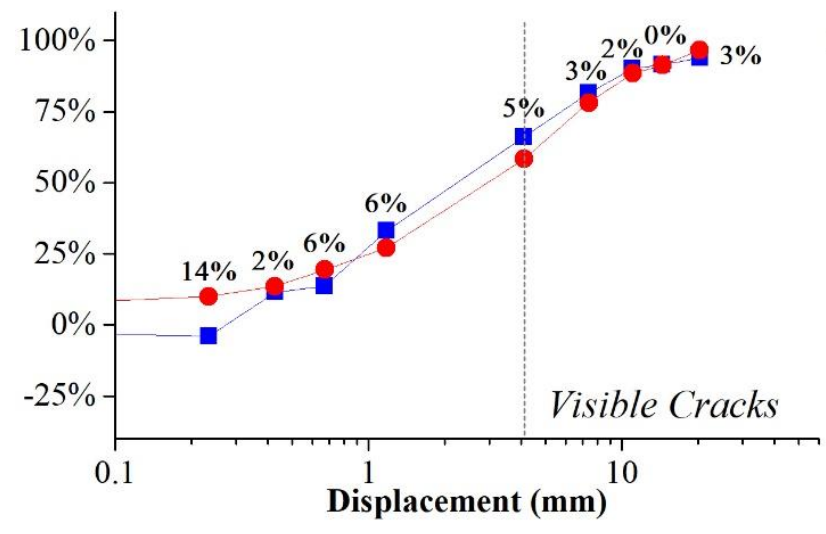

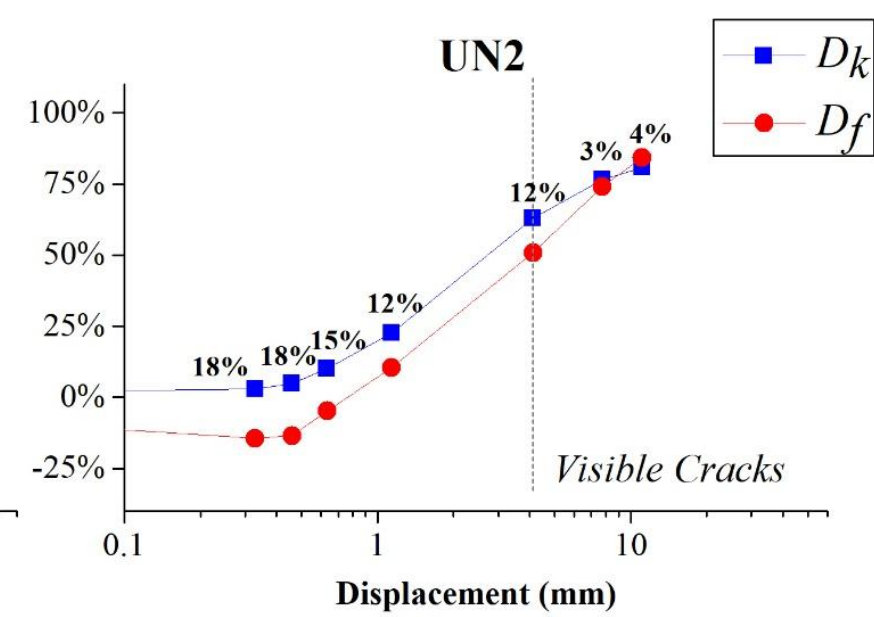

SE2

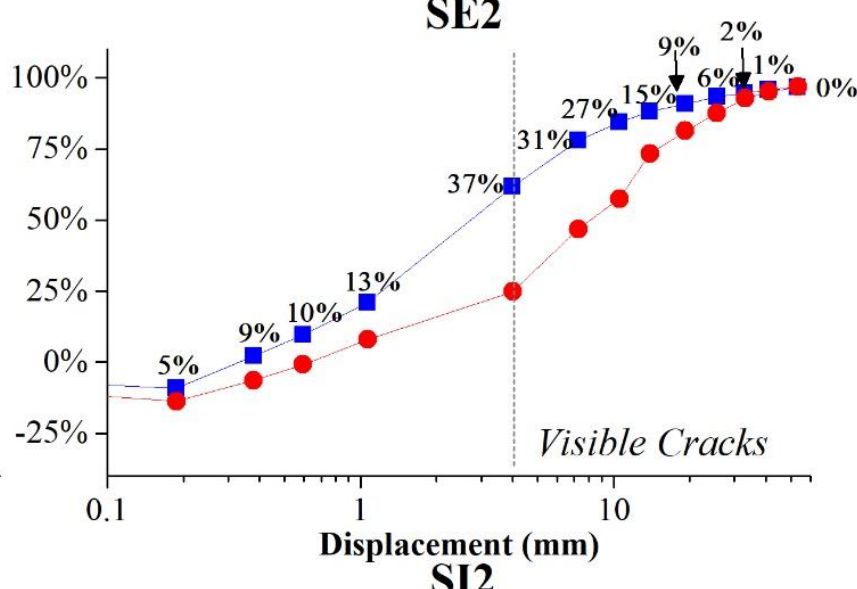

SI2

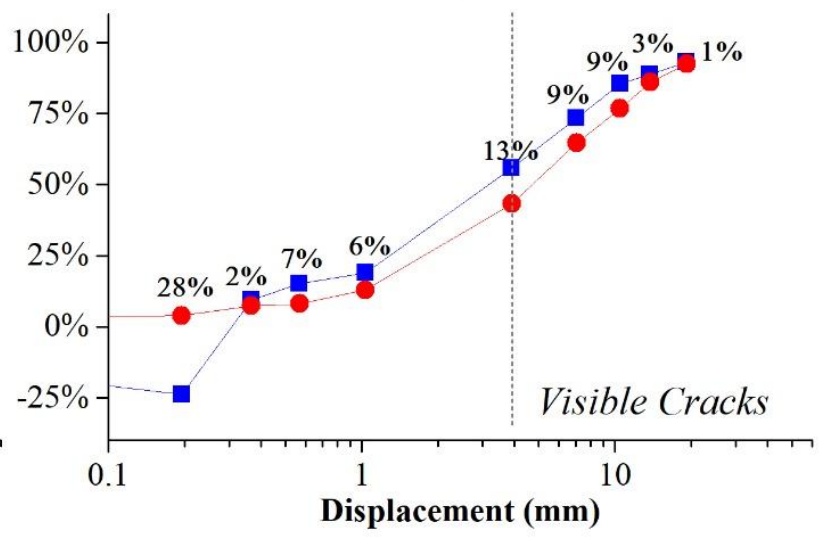

RSI2

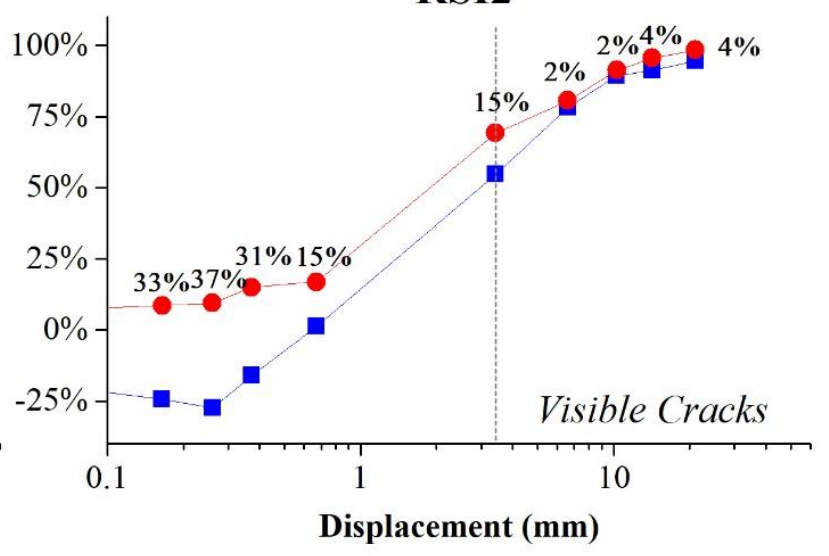




\section{Numerical Validation}

To verify the replicability and broader applicability of the proposed damage index $D_{f}$ to other types of arch collapse mechanisms, the experimental validation procedure described in the previous Section is here repeated using the numerical results from a similar masonry arch reproduced numerically, but analyzing different collapse modes.

DIANA FEA software [45] is employed to build the numerical model of an adobe arch with the same dimensions as the tested specimens. The geometric domain is discretized using twentynode brick elements (CHX60), for a total of 8,480 elements, 42,053 nodes and 124,425 degrees of freedom (Figure 9). The $25 \mathrm{~kg}$ cement bags used during the experiment to apply pre-compression at the arch key are numerically simulated through added masses. Although the simplicity of the arch geometry could allow for a 2-D analysis, a 3-D model was preferred for this study in order to estimate both in-plane and out-of-plane vibration modes and consider the most significant ones for the damage identification process in terms of frequency reduction.
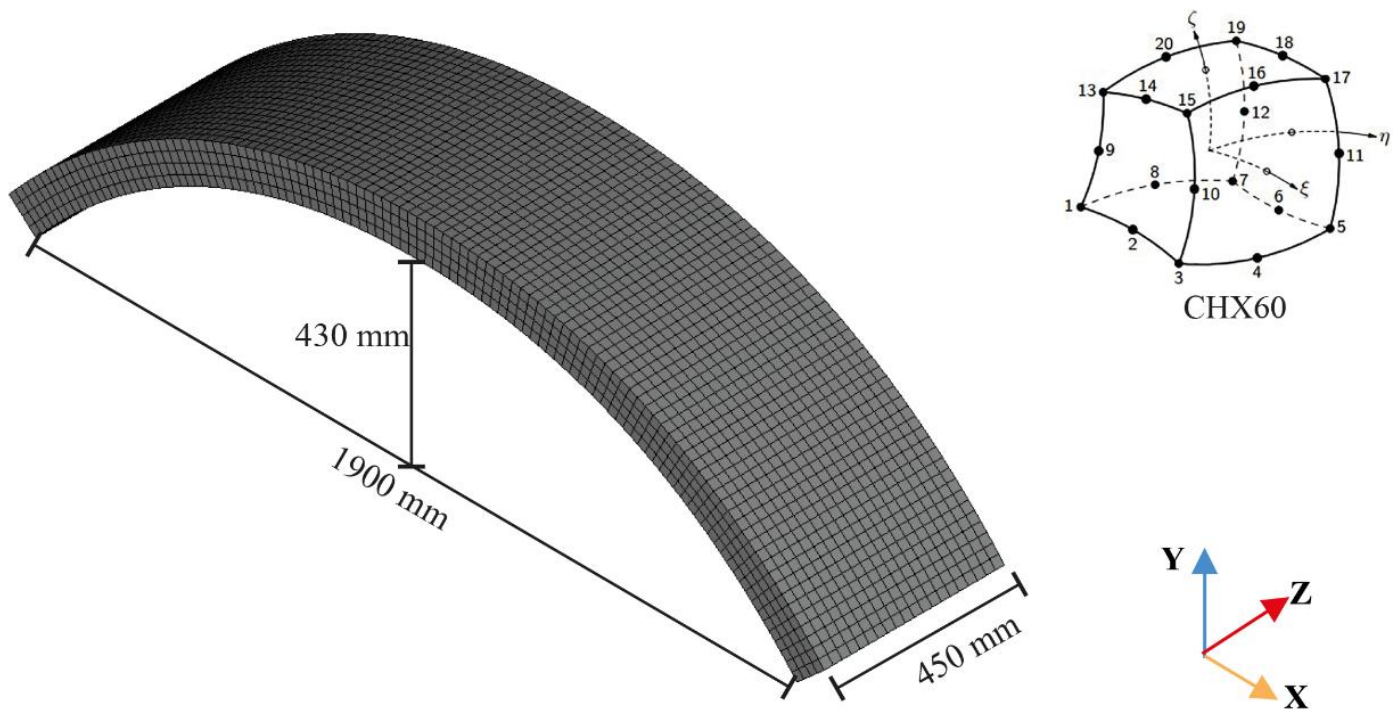

Figure 9 Finite element model of the arch.

\subsection{Calibration of the numerical model}

Aiming at identifying the actual mechanical properties of the materials used for the experimental tests, the first operation performed on the numerical model was its calibration, taking the unreinforced arch in undamaged condition (UN 1) as reference. To this end, a modal-based model updating procedure based on the Douglas and Reid methodology (DR) [46] was carried out on the FE model to match the first three numerical vibration modes with their experimental counterpart. The DR's approach consists in identifying the values of the uncertain parameters of the model by minimizing an objective function, which is based on the difference between numerical and experimental frequencies.

As starting hypotheses, both the specific weight, whose value was obtained during the experimental campaign [33-35], and the Poisson's coefficient were considered as fixed parameters for the updating process with values equal to $1.48 \mathrm{kN} / \mathrm{m}^{3}$ and 0.2 , respectively. As for the adobe material, an orthotropic behavior was assumed, hypothesis that is in line with what demonstrated in the literature for rammed earth $[47,48]$, i.e. the importance of considering different elastic modules in the three directions if this material is lightly loaded. 
From these assumptions, the unknown parameters to calibrate resulted to be the elastic moduli $\left(E_{x}, E_{y}, E_{z}\right)$ and the shear moduli $\left(G_{x y}, G_{y z}, G_{z x}\right)$ of the adobe material. As indicated in the DR's methodology, reasonable ranges based on literature values $[49,50]$ were defined for the aforementioned variables, setting for each of them an initial value $X^{0}$, an upper bound $X^{U}$ and a lower bound $X^{L}$ (Table 4).

Table 4 Range of updating parameters set for the numerical model calibration.

\begin{tabular}{cccc}
\hline & $\mathrm{X}^{0}[\mathrm{MPa}]$ & $\mathrm{X}^{\mathrm{L}}[\mathrm{MPa}]$ & $\mathrm{X}^{\mathrm{U}}[\mathrm{MPa}]$ \\
\hline $\mathbf{E}_{\mathbf{x}}$ & 1150 & 1050 & 1250 \\
$\mathbf{E}_{\mathbf{y}}$ & 275 & 250 & 300 \\
$\mathbf{E}_{\mathbf{z}}$ & 80 & 50 & 110 \\
$\mathbf{G}_{\mathbf{x y}}$ & 300 & 275 & 325 \\
$\mathbf{G}_{\mathbf{y z}}$ & 70 & 50 & 90 \\
$\mathbf{G}_{\mathbf{z x}}$ & 260 & 220 & 300 \\
\hline
\end{tabular}

A step-by-step sensitivity analysis was performed first in order to understand which of the unknown parameters influenced most the modal behavior of the arch model. Starting from the numerical model with all $X^{0}$ values set for the updating variables, subsequent eigenvalue analyses were run changing only one parameter at the time, namely beginning with their maximum and minimum values and then gradually reducing the range around the initial value. Figure 10 shows, for each parameter reported in Table 4, the percentage errors of the first three frequencies of the numerical model with respect to the experimental values. It is worth noting that the $1^{\text {st }}$ vibration mode, i.e. the out-of-plane bending in $\mathrm{Z}$ direction (Figure 11), is mainly influenced by the shear stiffness of the adobe material, especially by the shear modulus $G_{y z}$, while the $2^{\text {th }}$ mode, i.e. the asymmetrical vertical bending in $\mathrm{Y}$ direction (Figure 11), is mainly sensitive to $E_{x}$ and $E_{y}$, as expected given its in-plan deformation, but also to $G_{x y}$. Finally, the $3^{\text {rd }}$ vibration mode (Figure 11) results strongly dependent on $E_{x}$ and $G_{x y}$ variations. 


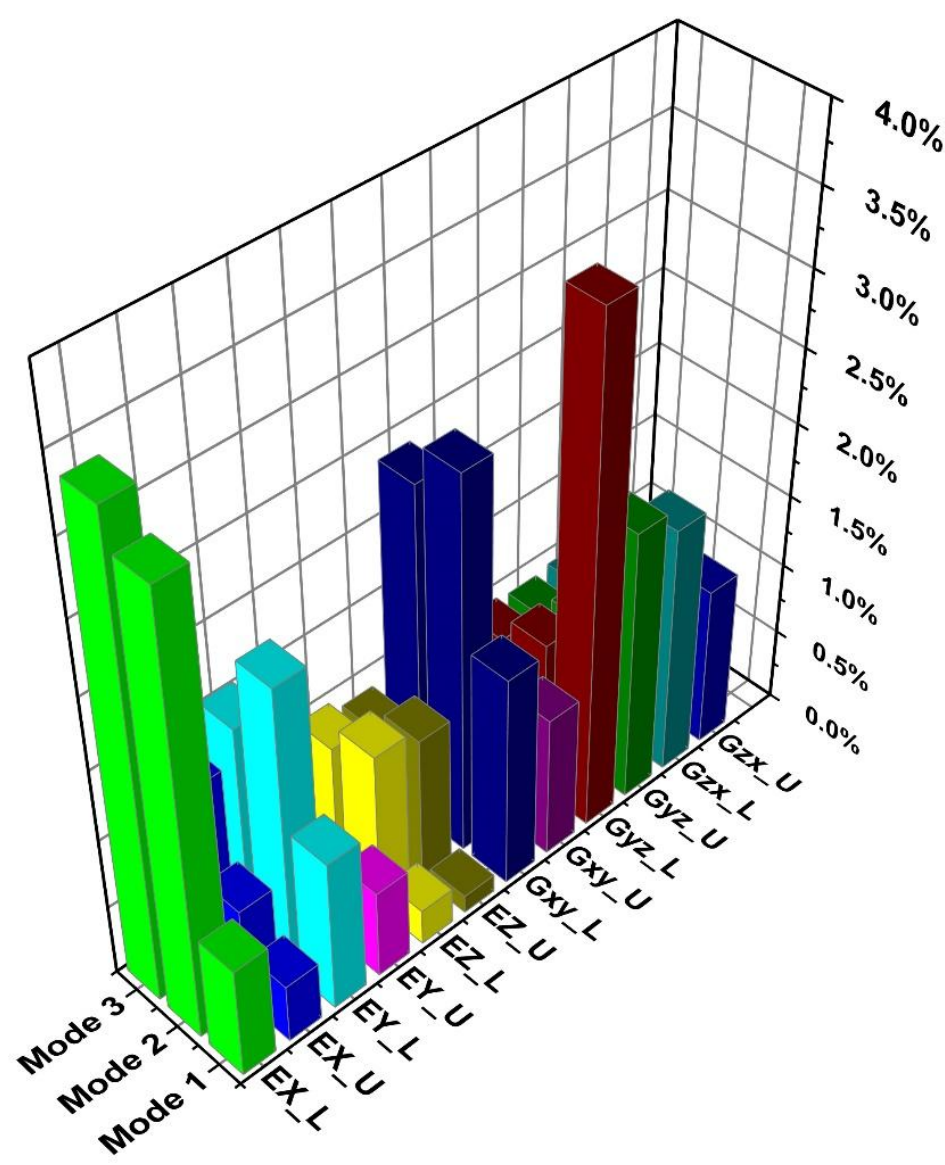

Figure 10 Sensitivity of the numerical model to variations in the updating parameters. The influence of each parameters is expressed as percentage difference between numerical and experimental frequencies of the first three modes.

This procedure allowed to progressively tune the numerical model, minimizing the difference with the experimental results up to reaching an average frequency error of $0.36 \%$. The final values of the updating parameters are reported in Table 5.

Table 5 Updated parameters of the calibrated numerical model.

\begin{tabular}{cccccc}
$\mathrm{E}_{\mathrm{x}}[\mathrm{MPa}]$ & $\mathrm{E}_{\mathrm{y}}[\mathrm{MPa}]$ & $\mathrm{E}_{z}[\mathrm{MPa}]$ & $\mathrm{G}_{\mathrm{xy}}[\mathrm{MPa}]$ & $\mathrm{G}_{\mathrm{yz}}[\mathrm{MPa}]$ & $\mathrm{G}_{\mathrm{zx}}[\mathrm{MPa}]$ \\
\hline 1155.5 & 276.2 & 80.1 & 308.8 & 64.3 & 262.8
\end{tabular}

In addition to the calibration of the bfrequencies, the degree of correlation between experimental and numerical modal vectors was also checked using the MAC. The computed values showed a very good correlation between mode shapes, having an average MAC of 0.99 for the second and third mode, and a minimum MAC value equal to 0.98 for the first mode. Figure 11 shows the modal results of the calibrated numerical model in terms of frequencies, mode shapes and MAC values along with the percentage frequency error with respect to the experimental values. 
MODE 1
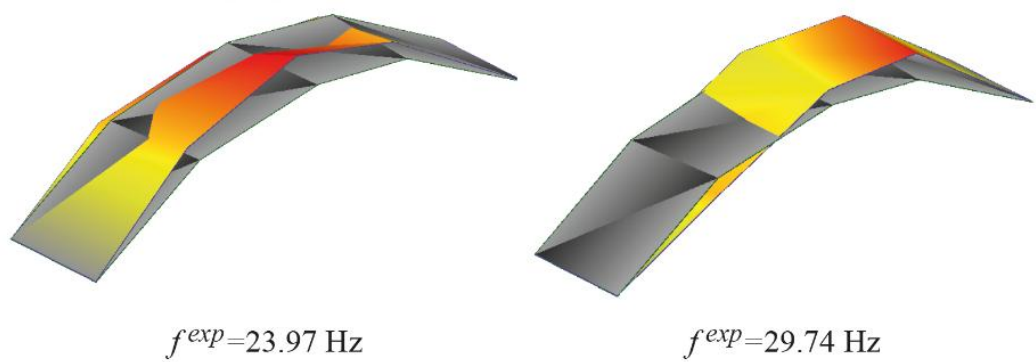

$f^{\exp }=29.74 \mathrm{~Hz}$

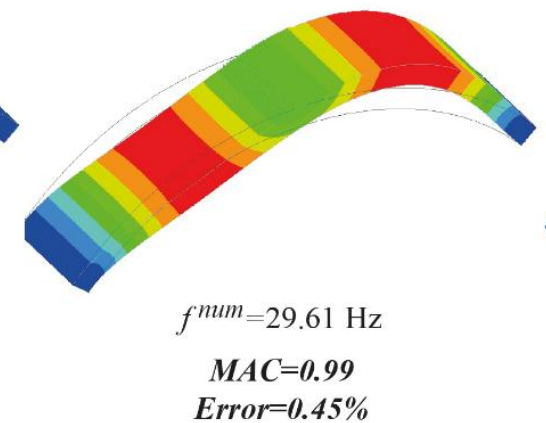

MODE 3
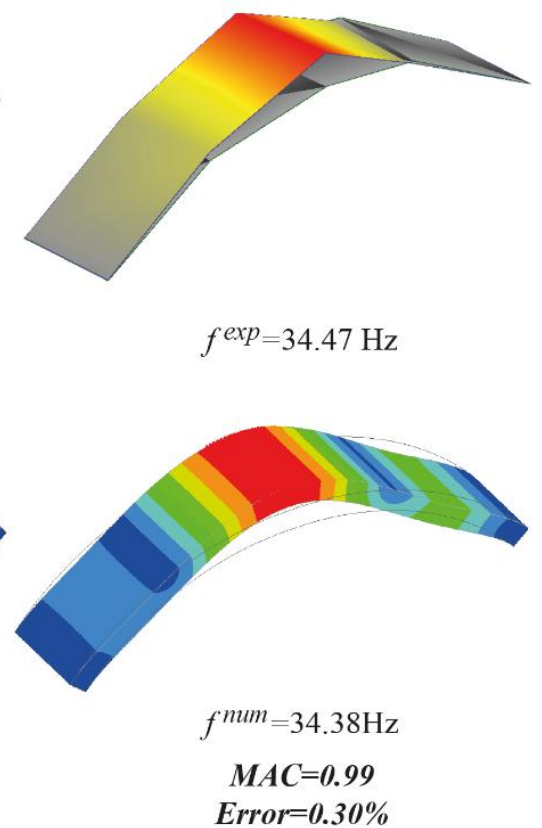

Figure 11 Comparison between experimental (top) and numerical (bottom) modes of vibration for the reference arch.

\subsection{Nonlinear static analysis}

After calibration, different nonlinear static analyses were carried out in order to verify that the experimentally validated damage index was also applicable to other types of collapse mechanisms that may occur in vaults and arches.

In order to represent damage-induced changes in the modal frequencies of the arch model, a nonlinear behavior was defined for the adobe material. Given the impossibility to adopt the total strain crack model for the orthotropic materials, since the software used has not yet implemented, the adobe was modelled as isotropic. First, the cracked value of the $E_{x}\left(E_{x} / 2=578 \mathrm{MPa}\right)$, based on a displacement-based approach for the structural assessment of existing masonry structures (simulation of an arch in an ancient structure) was considered. Then, the Young's modulus obtained from destructive laboratory tests performed on adobe panels (480 MPa) was also considered [33]. Furthermore, the average value of $E_{x}, E_{y}$ and $E_{z}(504 \mathrm{MPa})$ was calculated. Since all the values are similar, a Young's modulus equal to $578 \mathrm{MPa}$ was adopted. It is noted that this numerical application represents a theoretical case study adopted only for the evaluation of the damage index. Both mass density and Poission's coefficient were not changed. For the nonlinear analyses, the weight of the cement bags was modeled as a load applied at the arch extrados. The alterations on the mode shapes and frequencies, with respect to the model with orthotropic behavior (Figure 11), can be observed in the Figure 14, which are not revelant for the validation of the damage index.

The nonlinear behavior of the adobe was described using the Total Strain Rotating Crack model with a parabolic stress-strain curve in compression and a Hordijk stress-strain curve in tension (Figure 12), being these the common relationships used when describing the masonry constitutive behavior [51,52]. In these constitutive laws, it was necessary to define the tensile $\left(f_{t}\right)$ and compressive $\left(f_{c}\right)$ strength as well as their respective fracture energies $\left(G_{f}, G_{c}\right)$. 

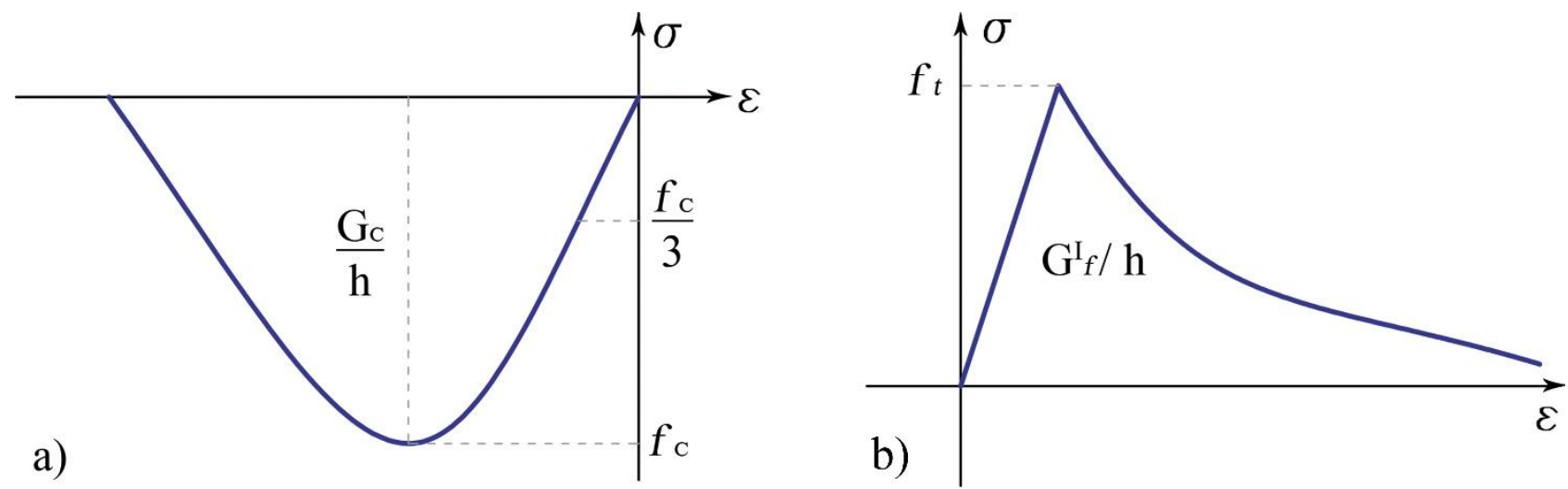

Figure 12 Constitutive laws adopted for the adobe material: a) stress-strain curve in compression; b) stress-strain curve in tension

To this end, the value of compressive strength $f_{c}$ obtained from previous laboratory tests [33] was adopted in the model; while the tensile strength $f_{t}$ was considered equal to $10 \%$ of $f_{c}$; as for the fracture energies, the values were defined taking into consideration those reported in previous studies on analogous material [53,54]. Table 6 summarizes both the linear and nonlinear parameters adopted for the numerical analysis.

Table 6 Material properties adopted in the numerical model for the nonlinear static analyses.

\begin{tabular}{|c|c|c|c|}
\hline ELASTIC & INE & R PARAM & TERS \\
\hline$\rho[\mathrm{kg} / \mathrm{n}$ & & 1480 & \\
\hline $\mathrm{E}[\mathrm{MP}$ & & 578 & \\
\hline $\mathrm{n}$ & & 0.2 & \\
\hline NONLI & IEAR & ARAMETI & \\
\hline Paraboli & law & Hordjik & law \\
\hline $\mathrm{f}_{\mathrm{c}}[\mathrm{MPa}]$ & 0.65 & $\mathrm{f}_{\mathrm{t}}[\mathrm{MPa}]$ & 0.065 \\
\hline $\mathrm{G}_{\mathrm{c}}[\mathrm{N} / \mathrm{mm}]$ & 1.04 & $\mathrm{G}_{\mathrm{f}}[\mathrm{N} / \mathrm{mm}]$ & 0.02 \\
\hline $\mathrm{h}[\mathrm{mm}]$ & 22.1 & & \\
\hline
\end{tabular}

Two nonlinear static analyses were carried out: i) one to simulate a failure condition due to symmetrical horizontal displacement at both supports (out-of-plane deformation of walls or abutments); and ii) one to replicate a collapse mechanism due to a distributed load. For the first condition analyzed, opposite horizontal displacements of $+/-1 \mathrm{~mm}$ were imposed at the base nodes. In the second case, a uniform distributed load $(q)$ of $1 \mathrm{kN} / \mathrm{m}^{2}$ was applied on the arch and increased until collapse, causing a five-hinge mechanism.

\subsection{Discussion of the results}

The load-displacement capacity curves of a selected node in the keystone were first assessed (Figure 13a-b). Observing the curve representative of the three-hinge mechanism induced by the horizontal displacement at the supports, it is noted that the arch presents a brittle behavior with a sudden collapse after the reaching the maximum load capacity. The maximum displacement 
obtained in the analysis is equal to $6 \mathrm{~mm}$. In what concern the curve representative of the five-hinge mechanism, activated by the increased vertical distributed load, a different behavior is observed, being the collapse reached only for an ultimate vertical displacement of $14 \mathrm{~mm}$ after a long stability phase, in which the thrust line still lied inside the arch profile.
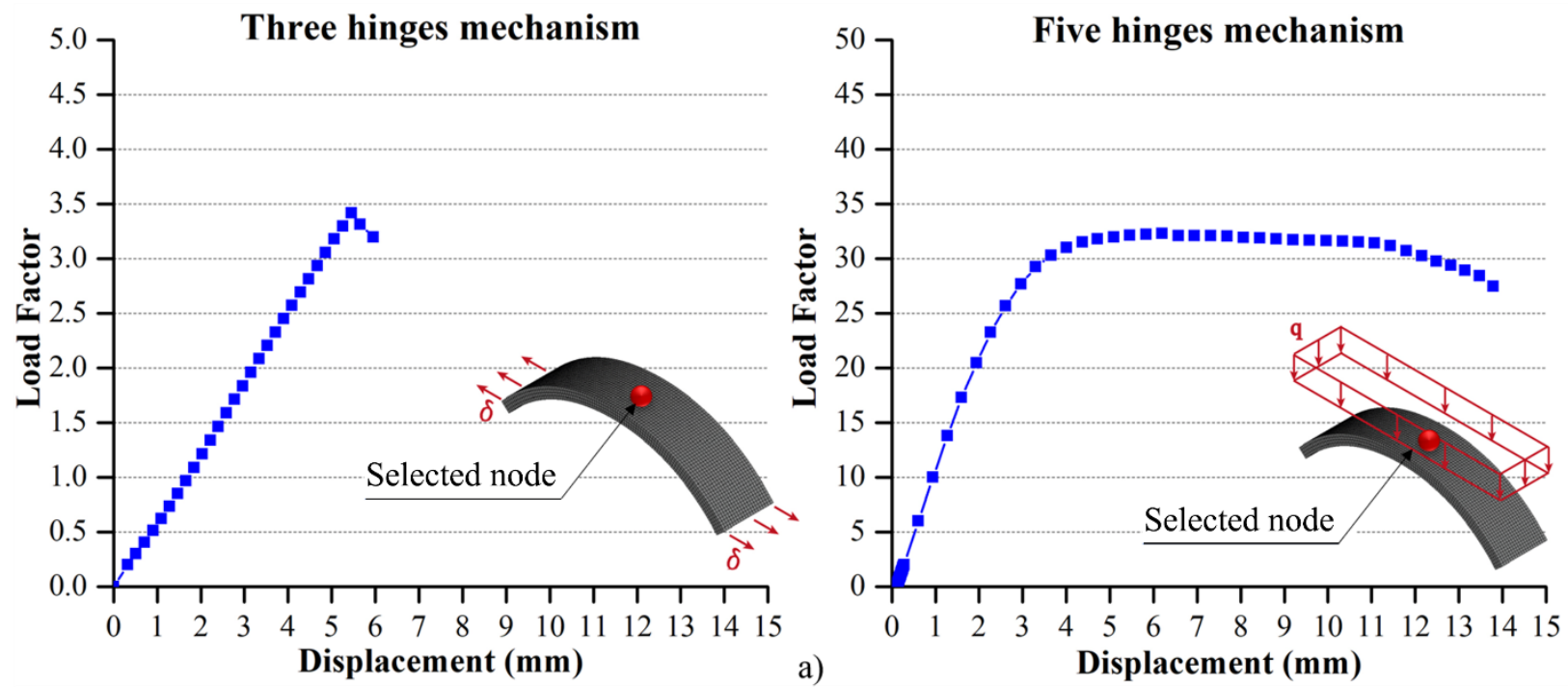

b)

Figure 13 Arch capacity curves: a) Three hinges mechanism; b) Five hinges mechanism.

In order to proceed with the numerical validation of the proposed damage index, based on the capacity curves, several load steps (31 for the three-hinge mechanism and 39 for the five-hinge mechanism) were chosen and the damaged model corresponding to each of these steps was subjected to eigenvalues analysis, considering the tangent stiffness matrix with respect to the previous state. This allowed to estimate the modal properties of the arch over progressive damage conditions. For comparison purposes, only the first three vibration modes were considered: (i) asymmetrical vertical bending; (ii) out-of-plane lateral bending; (iii) symmetrical vertical bending. Frequency values and modal shapes of the arch in its initial state are displayed in Figure 14. Although the numerical mode sequence and frequencies in this case did not correspond exactly to the experimental one, this discrepancy was not relevant in the framework of the index validation.

\section{MODE 1}

\section{Vertical asymmetric bending}

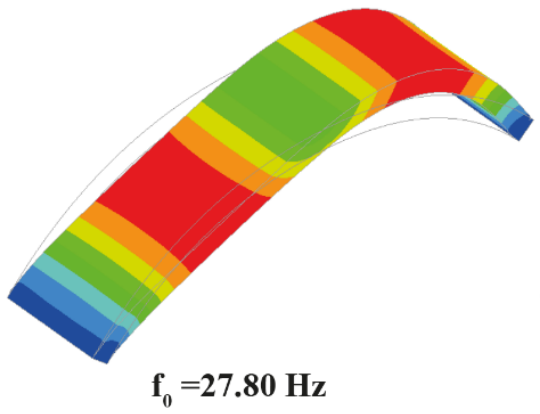

MODE 2

Out-of-plane bending

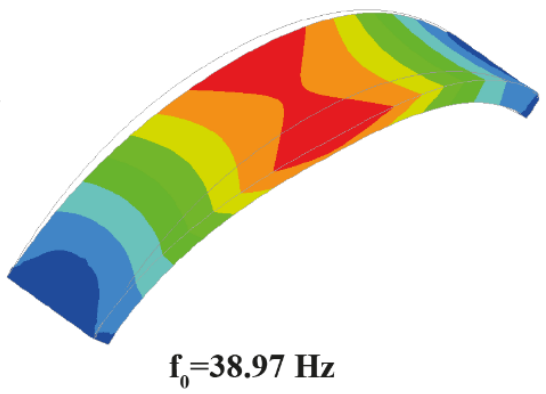

MODE 3

Vertical symmetric bending

Figure 14 Initial modes of the numerical model.

For each analysed step, the numerical frequencies of the damaged model were estimated and used to compute the damage index $D_{f}$ according to Eq. (8), taking the frequencies shown in Figure 14 as reference values for the denominator. Once again, the damage index seems able to adequately represent the global stiffness degradation of the arch for both types of mechanisms (Figure 15). 
In case of horizontal displacements at the supports, the most affected mode by the stiffness loss presenting a damage index already higher than $50 \%$ for a vertical displacement of $1.47 \mathrm{~mm}$ (load factor 0.85 ) in contrast with the second and third modes that reached this value for $1.84 \mathrm{~mm}$ and $1.66 \mathrm{~mm}$ (load factors 1.09 and 0.97 ), respectively. The first cracks occur at the extrados of both supports, for a vertical displacement of $0.5 \mathrm{~mm}$ (load factor 0.3 ) and $D_{f}=6 \%$, and then they increase simultaneously with the formation of the crack at intrados (first intrados slits occur for a load factor of 0.73 and $D_{f}=45 \%$ ). From Figure 155a, it is observed that no concentration of stresses occurs at the intrados. The stresses are distributed over an extended area, hence the remarkable high value of the damage index for all three modes.

On the other hand, the collapse due to vertical distributed load is more complex. In the initial stages, modes 1 and 3, i.e. the asymmetrical and symmetrical vertical bending modes, respectively, are those showing a greater stiffness decrease, thus higher values of $D_{f}$; then, as damage becomes more severe and high stresses are simultaneously reached at all crack hinges $\left(D_{f}=50 \%\right)$, the damage index records an abrupt increase, especially as far as the second mode is concerned, reaching a $D_{f}=90 \%$ at the collapse limit (Figure 15b). The first cracks occur at the intrados of the supports for a vertical displacemenet of $2.96 \mathrm{~mm}$ (load factor of 27.68) $\left(D_{f}=16 \%\right.$ for the first mode, $D_{f}=3 \%$ for the second mode and $D_{f}=9 \%$ for the third mode); subsequently, these cracks continue to increase and a third hinge appears at the intrados of the keystone $\left(D_{f}=29 \%\right.$ for the first mode, $D_{f}=16 \%$ for second the mode and $D_{f}=27 \%$ for the third mode). Finally, for a vertical displacement of $11.07 \mathrm{~mm}$ (load factor of 31.42), two symmetric cracks begin to form at the extrados of the arch haunches $\left(D_{f}=58 \%\right.$ for the first mode, $D_{f}=60 \%$ for the second and third mode). From this stage on, the stiffness loss due to the five cracks mainly affects the symmetrical modal response of the arch, both out-of-plane (mode 2) and in-plane (mode 3). In any case, the damage index based on the first mode is also a good indicator to evaluate loss stiffness of the arch, mainly for the initial damage, including for the damage index equal to $50 \%$.
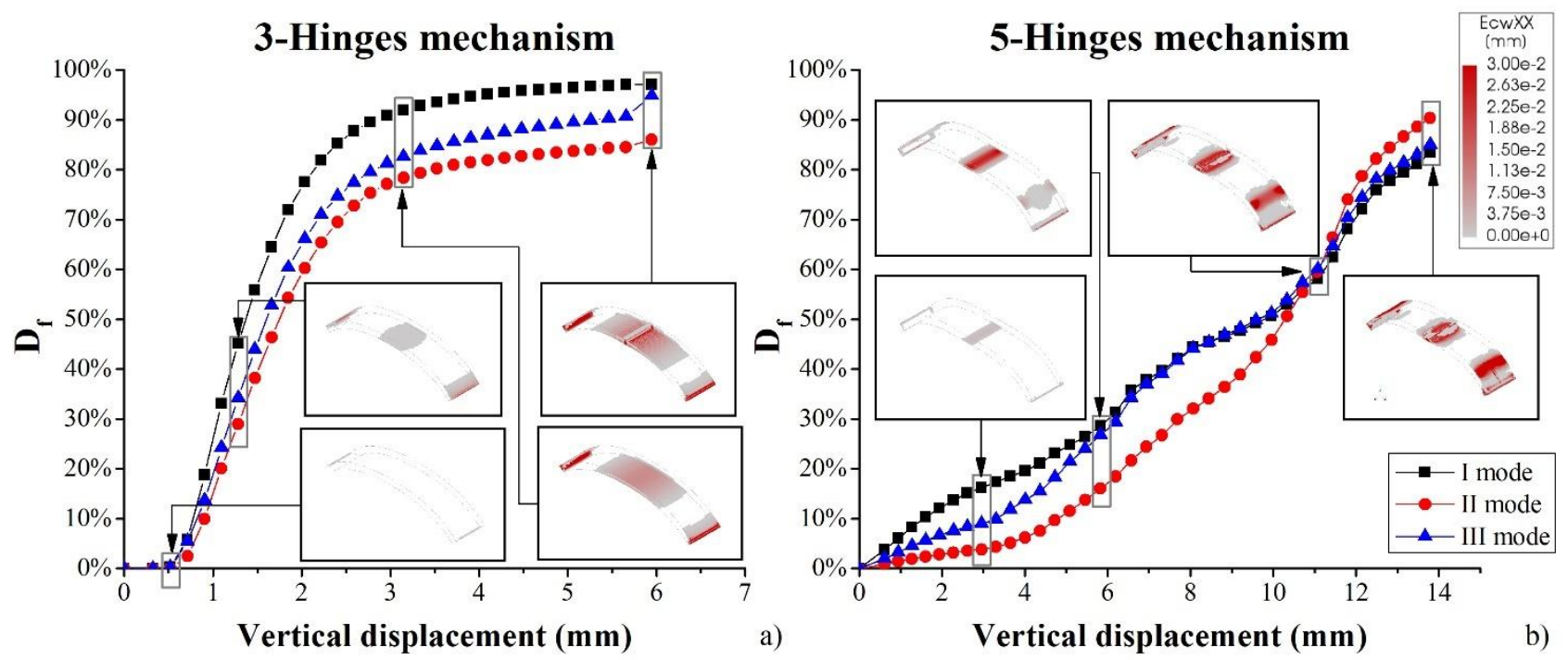

Figure 15 Damage index evolution with progressive cracking: a) three hinges mechanism; b) five hinges mechanism.

\section{Conclusions}

The main objective of this work was to elaborate an index capable of following and assessing the structural damage in arched systems using a supervised approach, i.e. with respect to a reference condition, considering that these structures are mainly damaged by bending moments. The aim was driven by the necessity to find a simple yet effective damage index, applicable in the engineering 
practice to keep these structural systems under control during their entire life cycle (monitoring) and severe damage occurs. Since the dynamic parameters of structures are sensitive to damage, the frequencies were chosen as key modal indicators for the definition of the index, considering also that these parameters are easily identifiable even with a reduced number of sensors.

To achieve this goal experimental and numerical data were used. The experimental data were obtained by pseudo-static laboratory tests executed on eight adobe arches, either unreinforced or reinforced with TRM. The arches were subjected to increasing cycles of vertical displacement at third span to induce different damage scenarios; at the end of each cycle, a dynamic identification test was performed for the progressive evaluation of modal parameters. The estimated frequencies were used to elaborate and verify the reliability of a new damage index $D_{f}$, expressed as a function of the frequency ratio between damaged and undamaged scenarios. The direct comparison with a stiffness-based degration index $D_{k}$, calculated as a function of the reduction of the tangent stiffness along the tests, demonstrated that in most cases the $D_{f}$ index is able to satisfactorily follow the stiffness loss of the arches due to progressive damage.

To evaluate the applicability of the proposed index also for other types of collapse mechanisms of arched structures, a numerical work was carried out. Two common arch failures were simulated following the same procedure of the experimental tests. The loading cycles were reproduced by non-linear static analyses and the varying frequencies were obtained at each cycle from an eigenvalue analysis, carried out considering the residual tangent stiffness after each non-linear analysis. The results of the numerical models validated the capability of the index to follow the stiffness degradation and strength reduction of the adobe arches.

In conclusion, it is shown that the proposed frequency-based index is able to identify and quantify the structural damage in all analysed arched systems, both experimentally and numerically, using just a few sensors, provided that they are sufficient in number to catch the first and most meaningful vibration modes for the considered/expected damage scenario. In fact, for the present case studies, the sole identification of the vertical asymmetric bending mode - which turned out to be the most susceptible to the induced damage - could be enough for damage identification purposes.

\section{References}

[1] M. Valente, G. Milani, Seismic assessment of historical masonry towers by means of simplified approaches and standard FEM, Constr. Build. Mater. 108 (2016) 74-104. doi:10.1016/j.conbuildmat.2016.01.025.

[2] M. Acito, C. Chesi, G. Milani, S. Torri, Collapse analysis of the Clock and Fortified towers of Finale Emilia, Italy, after the 2012 Emilia Romagna seismic sequence: Lesson learned and reconstruction hypotheses, Constr. Build. Mater. 115 (2016) 193-213. doi:10.1016/j.conbuildmat.2016.03.220.

[3] S.W.S. Doebling, C.R.C. Farrar, M.B.M. Prime, D.W.D. Shevitz, Damage identification and health monitoring of structural and mechanical systems from changes in their vibration characteristics: a literature review, Los Alamos Natl. Lab. (1996). doi:10.2172/249299.

[4] C. Gentile, A. Saisi, Ambient vibration testing of historic masonry towers for structural identification and damage assessment, Constr. Build. Mater. (2007). doi:10.1016/j.conbuildmat.2006.01.007. 
[5] A. De Stefano, E. Matta, P. Clemente, Structural health monitoring of historical heritage in Italy: some relevant experiences, J. Civ. Struct. Heal. Monit. (2016). doi:10.1007/s13349016-0154-y.

[6] F. Ubertini, G. Comanducci, N. Cavalagli, Vibration-based structural health monitoring of a historic bell-tower using output-only measurements and multivariate statistical analysis, Struct. Heal. Monit. (2016). doi:10.1177/1475921716643948.

[7] F. Clementi, A. Pierdicca, A. Formisano, F. Catinari, S. Lenci, Numerical model upgrading of a historical masonry building damaged during the 2016 Italian earthquakes: the case study of the Podestà palace in Montelupone (Italy), J. Civ. Struct. Heal. Monit. 7 (2017) 703-717. doi:10.1007/s 13349-017-0253-4.

[8] E. Giordano, F. Clementi, A. Barontini, M. Giovanna, E. Chatzi, F. Luís, Damage detection and optimal sensor placement in health monitoring of "Collegiata di Santa Maria " in Visso ( Central Italy ) Damage detection and optimal sensor placement in health monitoring of “" Collegiata di Santa Maria " in Visso ( Central Italy ), (2019) 44-53.

[9] I. Venanzi, A. Kita, N. Cavalagli, L. Ierimonti, F. Ubertini, Continuous OMA for Damage Detection and Localization in the Sciri tower in Perugia, Italy, in: IOMAC - Int. Oper. Modal Anal. Conf. 2019At Copenhagen, Denmark, Copenhagen, Denmark, 2019.

[10] F. Ubertini, G. Comanducci, N. Cavalagli, A. Laura Pisello, A. Luigi Materazzi, F. Cotana, Environmental effects on natural frequencies of the San Pietro bell tower in Perugia, Italy, and their removal for structural performance assessment, Mech. Syst. Signal Process. (2017). doi:10.1016/j.ymssp.2016.05.025.

[11] N. Cavalagli, G. Comanducci, F. Ubertini, Earthquake-Induced Damage Detection in a Monumental Masonry Bell-Tower Using Long-Term Dynamic Monitoring Data, J. Earthq. Eng. 22 (2018) 96-119. doi:10.1080/13632469.2017.1323048.

[12] L.F. Ramos, G. De Roeck, P.B. Lourenço, A. Campos-Costa, Damage identification on arched masonry structures using ambient and random impact vibrations, Eng. Struct. 32 (2010) 146-162. doi:10.1016/j.engstruct.2009.09.002.

[13] A. Alvandi, C. Cremona, Assessment of vibration-based damage identification techniques, J. Sound Vib. (2006). doi:10.1016/j.jsv.2005.07.036.

[14] Y.J. Yan, L. Cheng, Z.Y. Wu, L.H. Yam, Development in vibration-based structural damage detection technique, Mech. Syst. Signal Process. 21 (2007) 2198-2211. doi:10.1016/j.ymssp.2006.10.002.

[15] S. Das, P. Saha, S.K. Patro, Vibration-based damage detection techniques used for health monitoring of structures: a review, J. Civ. Struct. Heal. Monit. 6 (2016) 477-507. doi:10.1007/s 13349-016-0168-5.

[16] J.J. Sinou, A review of damage detection and health monitoring of mechanical systems from changes in the measurement of linear and non-linear vibrations, Mech. Vib. Meas. Eff. Control. (2009) 643-702.

[17] Ritter, Aalborg Universitet Vibrational Based Inspection of Civil Engineering Structures Rytter, Anders, (1993).

[18] C. Gentile, A. Ruccolo, F. Canali, Long-term monitoring for the condition-based structural maintenance of the Milan Cathedral, Constr. Build. Mater. 228 (2019) 117101. doi:10.1016/j.conbuildmat.2019.117101. 
[19] L.F. Ramos, P.B. Lourenço, G. De Roeck, A. Campos-Costa, Damage identification in masonry structures with vibration measurements, Struct. Anal. Hist. Constr. Preserv. Saf. Significance - Proc. 6th Int. Conf. Struct. Anal. Hist. Constr. SAHC08. 1 (2008) 311-319. doi:10.1201/9781439828229.ch35.

[20] M. Dahak, N. Touat, M. Kharoubi, Damage detection in beam through change in measured frequency and undamaged curvature mode shape, Inverse Probl. Sci. Eng. 27 (2019) 89-114. doi:10.1080/17415977.2018.1442834.

[21] R. Brincker, P.H. Kirkegaard, J.P. Ulfkjaer, Damage Detection in laboratory concrete beams, 13th Int. Modal Anal. Conf. 1; (1995) 647-668.

[22] O. Yazdanpanah, S.M. Seyedpoor, H. Akbarzadeh Bengar, A new damage detection indicator for beams based on mode shape data, Struct. Eng. Mech. 53 (2015) 725-744. doi:10.12989/sem.2015.53.4.725.

[23] J.M. Ko, C.W. Wong, H.F. Lam, Damage detection in steel framed structures by vibration measurement approach, in: 12th Int. Modal Anal. Conf., 1994: pp. 280-286.

[24] M.G. Masciotta, L.F. Ramos, P.B. Lourenço, M. Vasta, Structural monitoring and damage identification on a masonry chimney by a spectral-based identification technique, Proc. Int. Conf. Struct. Dyn. , EURODYN. 2014-Janua (2014) 211-218.

[25] I. Venanzi, A. Kita, N. Cavalagli, L. Ierimonti, F. Ubertini, Earthquake-induced damage localization in an historic masonry tower through long-term dynamic monitoring and FE model calibration, Bull. Earthq. Eng. 18 (2020) 2247-2274. doi:10.1007/s10518-019-007804.

[26] M.G. Masciotta, L.F. Ramos, M. Vasta, P.B. Lourenço, Extraction of damage-sensitive eigen-parameters for supervised SHM, Procedia Eng. 199 (2017) 2178-2183. doi:10.1016/j.proeng.2017.09.174.

[27] A. Pau, A. Greco, F. Vestroni, Numerical and experimental detection of concentrated damage in a parabolic arch by measured frequency variations, JVC/Journal Vib. Control. 17 (2011) 605-614. doi:10.1177/1077546310362861.

[28] M.N. Cerri, G.C. Ruta, Detection of localised damage in plane circular arches by frequency data, J. Sound Vib. 270 (2004) 39-59. doi:10.1016/S0022-460X(03)00482-6.

[29] A. Greco, D. D’Urso, F. Cannizzaro, A. Pluchino, Damage identification on spatial Timoshenko arches by means of genetic algorithms, Mech. Syst. Signal Process. 105 (2018) 51-67. doi:10.1016/j.ymssp.2017.11.040.

[30] M. Ferraioli, L. Miccoli, D. Abruzzese, Dynamic characterisation of a historic bell-tower using a sensitivity-based technique for model tuning, J. Civ. Struct. Heal. Monit. 8 (2018) 253-269. doi:10.1007/s13349-018-0272-9.

[31] M.G. Masciotta, L.F. Ramos, P.B. Lourenço, M. Vasta, Spectral algorithm for nondestructive damage localisation: Application to an ancient masonry arch model, Mech. Syst. Signal Process. 84 (2017) 286-307. doi:10.1016/j.ymssp.2016.06.034.

[32] D. Brigante, M. Giovanna, C. Rainieri, G. Fabbrocino, P.B. Lourenço, Vibration-based damage identification with application to a scaled masonry Vibration-based damage identification with application to a scaled masonry, (2019) 10-20.

[33] N.H. Sadeghi, D. V Oliveira, M. Correia, Conservation and Safety Assessment of Vaulted Adobe Architecture in Yazd, Iran. PhD work performed under the supervision of Professor 
Daniel V . Oliveira, (2018).

[34] N. H. Sadeghi, D. V. Oliveira, M. Correia, H. Azizi-Bondarabadi, A. Orduña, Seismic performance of historical vaulted adobe constructions: a numerical case study from Yazd, Iran, Int. J. Archit. Herit. 12 (2018) 879-897. doi:10.1080/15583058.2017.1422573.

[35] N.H. Sadeghi, D. V Oliveira, R.A. Silva, N. Mendes, M. Correia, H. Azizi-bondarabadi, Performance of adobe vaults strengthened with LC-TRM: an experimental approach, in: Prot. Hist. Constr., Lisbon, Portugal, 2017.

[36] OPCM 3431/5, Primi elementi in materia di criteri generali per la classificazione sismica del territorio nazionale e di normative tecniche per le costruzioni in zona sismica, (2005).

[37] ARTeMIS Modal, Structural Vibration Solutions A/S, (2018).

[38] D.J. Ewins, Modal testing: theory and practice, J. Vib. Acoust. Stress Reliab. Des. (1986).

[39] British Standard Institution, BS 1881:Part 121, Method for determination of static modulus of elasticity in compression, (1997).

[40] ASTM C469/C469M, Standard Test Method for Static Modulus of Elasticity and Poisson's Ratio of Concrete in Compression, Astm C469/C469M. (2014) 1-5. doi:10.1520/C0469.

[41] GB/T50081-2002, Standard for tests method of mechanical properties on ordinary concrete, Minist. House Urban-Rulal Dev. People's Repub. China, China. (2002).

[42] S. Lenci, Q. Piattoni, F. Clementi, T. Sadowski, An experimental study on damage evolution of unfired dry earth under compression, Int. J. Fract. 172 (2011) 193-200. doi:10.1007/s10704-011-9651-5.

[43] S. Lenci, F. Clementi, Simple mechanical model of curved beams by a 3D approach, J. Eng. Mech. 135 (2009) 597-613. doi:10.1061/(ASCE)0733-9399(2009)135:7(597).

[44] J. Kubica, Proposition of stiffness reduction in analysis of clay brick masonry under cyclic/seismic loads, J. Meas. Eng. 6 (2018) 226-233. doi:10.21595/jme.2018.20417.

[45] DIANA, User's maual, (2019).

[46] B.M. Douglas, W.H. Reid, Dynamic tests and system identification of bridges, J. Struct. Div. 108 (1982) 2295-12.

[47] R.A. Silva, N. Mendes, D. V. Oliveira, A. Romanazzi, O. Domínguez-Martínez, T. Miranda, Evaluating the seismic behaviour of rammed earth buildings from Portugal: From simple tools to advanced approaches, Eng. Struct. 157 (2018) 144-156. doi:10.1016/j.engstruct.2017.12.021.

[48] Q.-B. Bui, J.-C. Morel, Assessing the anisotropy of rammed earth, Constr. Build. Mater. 23 (2009) 3005-3011. doi:10.1016/j.conbuildmat.2009.04.011.

[49] R. Illampas, R.A. Silva, D.C. Charmpis, P.B. Lourenço, I. Ioannou, Validation of the repair effectiveness of clay-based grout injections by lateral load testing of an adobe model building, Constr. Build. Mater. 153 (2017) 174-184. doi:10.1016/j.conbuildmat.2017.07.054.

[50] D. Silveira, H. Varum, A. Costa, T. Martins, H. Pereira, J. Almeida, Mechanical properties of adobe bricks in ancient constructions, Constr. Build. Mater. 28 (2012) 36-44. doi:10.1016/j.conbuildmat.2011.08.046.

[51] E. Giordano, F. Clementi, A. Nespeca, S. Lenci, Damage Assessment by Numerical Modeling of Sant'Agostino's Sanctuary in Offida During the Central Italy 2016-2017 
Seismic Sequence, Front. Built Environ. 4 (2019). doi:10.3389/fbuil.2018.00087.

[52] E. Giordano, F. Clementi, G. Cocchi, L. Marcheggiani, On the nonlinear behaviour of unfired dry earth, in: 2019: p. 100007. doi:10.1063/1.5138013.

[53] P.B. Lourenço, Recent advances in masonry modelling: micromodelling and homogenisation, in: Multiscale Model. Solid Mech. Comput. Approaches, 2009: pp. 251294. doi:10.1142/9781848163089_0006.

[54] N. Mendes, P.B. Lourenço, Sensitivity analysis of the seismic performance of existing masonry buildings, Eng. Struct. 80 (2014) 137-146. doi:10.1016/j.engstruct.2014.09.005. 